\title{
Rainfall Estimation with an Operational Polarimetric C-Band Radar in the United Kingdom: Comparison with a Gauge Network and Error Analysis
}

\author{
V. N. BRINGI \\ Department of Electrical and Computer Engineering, Colorado State University, Fort Collins, Colorado \\ M. A. RiCO-RAMIREZ \\ Department of Civil Engineering, University of Bristol, Bristol, United Kingdom \\ M. THURAI \\ Department of Electrical and Computer Engineering, Colorado State University, Fort Collins, Colorado
}

(Manuscript received 29 October 2010, in final form 8 February 2011)

\begin{abstract}
The estimate of rainfall using data from an operational dual-polarized C-band radar in convective storms in southeast United Kingdom is compared against a network of gauges. Four different rainfall estimators are considered: reflectivity-rain-rate $(Z-R)$ relation, with and without correcting for rain attenuation; a composite estimator, based on (i) $Z-R$, (ii) $R\left(Z, Z_{\mathrm{dr}}\right.$ ), and (iii) $R\left(K_{\mathrm{dp}}\right)$; and exclusively $R\left(K_{\mathrm{dp}}\right)$. The various radar rain-rate estimators are developed using Joss disdrometer data from Chilbolton, United Kingdom. Hourly accumulations over radar pixels centered on the gauge locations are compared, with approximately 2500 samples available for gauge hourly accumulations $>0.2 \mathrm{~mm}$. Overall, the composite estimator performed the "best" based on robust statistical measures such as mean absolute error, the Nash-Sutcliffe coefficient, and mean bias, at all rainfall thresholds $(>0.2,1,3$, or $6 \mathrm{~mm})$ with improving measures at the higher thresholds of $>3$ and $>6 \mathrm{~mm}$ (higher rain rates). Error variance separation is carried out by estimating the gauge representativeness error using $4 \mathrm{yr}$ of gauge data from the Hydrological Radar Experiment. The proportion of variance of the radar-to-gauge differences that could be explained by the gauge representativeness errors ranged from $20 \%$ to $55 \%$ (for the composite rain-rate estimator). The radar error is found to decrease from approximately $70 \%$ at the lower rain rates to $20 \%$ at the higher rain rates. The composite rainrate estimator performed as well as can be expected from error variance analysis, at mean hourly rain rates of about $5 \mathrm{~mm} \mathrm{~h}^{-1}$ or larger with mean bias of $\sim 10 \%$ (underestimate).
\end{abstract}

\section{Introduction}

The operational use of dual-polarized C-band radars by national weather agencies has gained rapid momentum in the last several years, especially in Europe. This impetus has been largely based on, for example, identifying precipitation echoes from echoes of nonmeteorological origin, stable correction of attenuation due to rain, and improvement in the accuracy of rainfall estimation. Substantial work has been done and is still ongoing regarding methodologies for realizing these

Corresponding author address: V. N. Bringi, Dept. of Electrical and Computer Engineering, Colorado State University, Fort Collins, CO 80523-1373.

E-mail: bringi@engr.colostate.edu improvements, and the literature is too large to summarize here (e.g., prior to 2001, see Bringi and Chandrasekar 2001, and references therein; Ryzhkov et al. 2005b; Gourley et al. 2006, 2007).

One key application of dual-polarized radars at the operational frequency bands $(\mathrm{S}, \mathrm{C}$, and $\mathrm{X})$ is the radar-based rainfall input to hydrological models (e.g., Krajewski and Smith 2002, and references therein; Smith et al. 2007). It is well known that the accuracy of dualpolarized radar rainfall products improves with increasing rain intensity because the signatures of $Z_{\mathrm{dr}}$ and differential propagation phase $\Phi_{\mathrm{dp}}$ are very pronounced enabling self-adjustment of the rain-rate algorithms due to drop size distribution (DSD) variability to capture a variety of storm types and extreme events (Bringi and Chandrasekar 2001). At C and X bands, rain attenuation 
becomes increasingly a complicating factor with increasing rain intensity, and dual polarization offers stable attenuation correction procedures. Such procedures are currently being tested for operational systems (see, e.g., Vulpiani et al. 2008; Diss et al. 2009; Moreau et al. 2009, hereafter MTL).

A variety of C-band rain-rate algorithms have been proposed in the literature, depending on the application and/or based on measurement and parameterization error considerations. Most emphasize the fact that, in convective rain, the measured $Z_{h}$ and $Z_{\mathrm{dr}}$ have to be corrected for attenuation before estimating the rain rate (e.g., Testud et al. 2000; Gorgucci et al. 1996; Bringi et al. 2009; Gu et al. 2011). Although there is as yet no consensus on an estimation scheme, the proposed rain-rate algorithms fall broadly under three categories, viz., those that use, (i) the attenuation-corrected $Z$ in "tuned" or gauge-adjusted $Z-R$ relations; (ii) $Z_{h}, Z_{\mathrm{dr}}$, and/or $K_{\mathrm{dp}}$ in a composite (synthetic) manner; and (iii) those that use the C-band-derived specific attenuation along with estimate of the normalized intercept parameter $N_{0}^{*}\left(\right.$ or $\left.N_{w}\right)$ along the beam (Le Bouar et al. 2001; Ryzhkov et al. 2005a; Silvestro et al. 2009). In nearly all cases, the estimators are parametric in nature and often use power-law relations, where the coefficients/exponents are derived from scattering simulations using disdrometer measurements of the DSD (Bringi and Chandrasekar 2001, chapter 8). These parametric algorithms also depend on the statistics of the median volume or mass-weighted mean diameter $\left(D_{0}\right.$ or $\left.D_{m}\right)$ or of the normalized intercept parameter $N_{0}^{*}$ (or $N_{w}$ ). Generally, the scattering simulations assume (i) a mean axis ratio versus $D$ relation (Keenan et al. 2001; Brandes et al. 2003; Thurai et al. 2007) and (ii) Gaussian canting angle distribution (mean $=0$; $\sigma=5^{\circ}-10^{\circ}$ ) (Huang et al. 2008). An optimal estimation scheme was proposed by Hogan (2007) at S band, which continuously adjusts the coefficient of an a priori $Z-R$ relation to estimate $R$ by minimizing a cost function that forces the forward-calculated $Z_{\mathrm{dr}}$ and $\Phi_{\mathrm{dp}}$ to "agree" in a mean-square sense with the measurements. This scheme is currently being evaluated using an operational C-band radar (Figueras i Ventura et al. 2010).

Rain-rate algorithms based on disdrometer DSDs are derived from "point" measurements and are subject to representativeness errors when applied to the vastly larger radar resolution volume. In a research and semioperational environment with some "tuning" based on local rain climatology (e.g., tropical versus midlatitudes), the potential for improving rainfall measurements when compared against gauges has been demonstrated (e.g., Ryzhkov et al. 2005a; Bringi et al. 2009; Matrosov 2010). When such comparisons are done, it is usually assumed that gauges are the ground "truth," although the issue of gauge representativeness errors (i.e., how well the point gauge measurement can represent the areal or more precisely the resolution volume-averaged rainfall that is measured by radar) is an important consideration so that all the errors are not allocated to the radar-only estimates (Kitchen and Blackall 1992). The hydrology community has been active in this area, more so than the dual-polarized radar community, in placing the related "error variance separation" on a firm footing (Ciach and Krajewski 1999; Habib and Krajewski 2002). One reason is that in the past only a few sites existed that had a high-quality dual-polarized radar as well as a dense gauge network within the radar coverage with long time records available to do a thorough error variance separation. To the best of our knowledge, the only C-band polarimetric radar (CPOL) with both D-scale $(\sim 2 \mathrm{~km})$ and C-scale $(\sim 20 \mathrm{~km})$ quality-controlled gauge networks and long time record of observations (at least a decade) is the Darwin site in northern Australia managed by the then Bureau of Meteorology Research Centre (Keenan et al. 1998; May et al. 1999), mainly as a Tropical Rainfall Measuring Mission (TRMM) ground validation site. A number of studies have used data from CPOL and the Darwin gauge network to test different rain-rate and attenuation correction algorithms, which will be reviewed later in section 4 .

In this work, an operational C-band dual-polarized radar located in Thurnham, Kent, United Kingdom, is used to estimate rainfall and to compare it with a gauge network for summertime (mostly) convective rain. Four different rain-rate algorithms are evaluated: based on fixed $Z_{h}-R$ relations (i) with and (ii) without attenuation correction, (iii) a composite estimator using $Z_{h}, Z_{\mathrm{dr}}$, and $K_{\mathrm{dp}}$; and (iv) an estimator based on $K_{\mathrm{dp}}$ alone. The algorithms were derived using a Joss disdrometer (RD-80; Joss and Waldvogel 1967) located in Chilbolton in southern England (and operated by the Rutherford Appleton Laboratory), along with the latest experimental information available on drop axis ratio and canting angle distributions (Thurai and Bringi 2005; Thurai et al. 2007; Huang et al. 2008; Beard et al. 2010). The disdrometer data used were from three summer months (June-August 2007) and the DSDs were assumed to be also representative of rainfall in the radar coverage area (Kent, United Kingdom). The parameterization errors for the various rain-rate algorithms are calculated. The gauge representativeness errors are also calculated using four years of gauge data from the Hydrological Radar Experiment (HYREX; Moore et al. 2000). Additionally, the spatial correlation function was estimated from the gauge data. Following Habib and Krajewski (2002), an error variance separation analysis is used to explain the proportion of variance of the radar-gauge differences that could be 
attributed to the point-to-area variance of the gauges. The "radar error," as defined by Habib and Krajewski (2002), is also calculated along with estimates of the parameterization and measurement errors to see how much of the radar error can be explained by the aforementioned errors. This is followed by a discussion section that places our results in context with some past studies, which is further followed by a summary and conclusions.

\section{Data sources and processing}

\section{a. C-band radar}

The radar data used here are from an operational dualpolarized C-band radar located in Thurnham, Kent, United Kingdom (see Figs. 1a,b). The radar is operated by the Met Office and is part of their weather radar network. The radar was installed with the intent of providing improved rainfall estimates for hydrological applications that were supported by the U.K. Environmental Agency (Harrison et al. 2009). Table 1 lists the key system characteristics. Note that dualpolarization capability is based on simultaneous transmission of horizontal $(\mathrm{H})$ and vertical $(\mathrm{V})$ polarizations with equal power and simultaneous reception of the $\mathrm{H}$ and $\mathrm{V}$ components of the backscattered signal via two matched receivers.

The nominal system parameters used are pulse width of $2 \mu \mathrm{s}$, pulse repetition frequency (PRF) of $300 \mathrm{~Hz}$, gate spacing of $250 \mathrm{~m}$, and a total of 1020 gates per beam. A number of plan position indicator (PPI) sweeps at a predetermined set of elevation angles $\left(0.2^{\circ}, 0.7^{\circ}\right.$, $1.2^{\circ}, 2.0^{\circ}, 2.9^{\circ}, 4.9^{\circ}$, and $90^{\circ}$ ) are performed at a rotation rate of $13^{\circ} \mathrm{s}^{-1}$ and a beam spacing of $1^{\circ}$ : this set of PPI sweeps take $5 \mathrm{~min}$ to complete. Here we use data from the second sweep at elevation angle of $0.7^{\circ}$. The number of samples available for integration at each resolution volume is 23 because of the low PRF used.

Early on after installation in 2005, it was found that the copolar correlation coefficient $\rho_{\text {co }}$ between the $\mathrm{H}$ and $\mathrm{V}$ polarized signals was somewhat lower than expected (mean $\approx 0.94)$ in rain for the simultaneous transmit and receive mode of operation (e.g., the expected values are closer to 0.99 or higher in rain: e.g., as reported by Gourley et al. 2006). This led to quite high measurement error in $Z_{\mathrm{dr}}$ because the variance of $Z_{\mathrm{dr}}$ is proportional to $\left(1-\rho_{\mathrm{co}}^{2}\right)$ (see Bringi and Chandrasekar 2001, chapter $7)$. It is not entirely clear why, on average, the $\rho_{\text {co }}$ is so low in rain for the Thurnham radar.

Ensuring high quality of the dual-polarized radar data is important for the retrieval of rain rates. The processing steps used here closely follow those described in

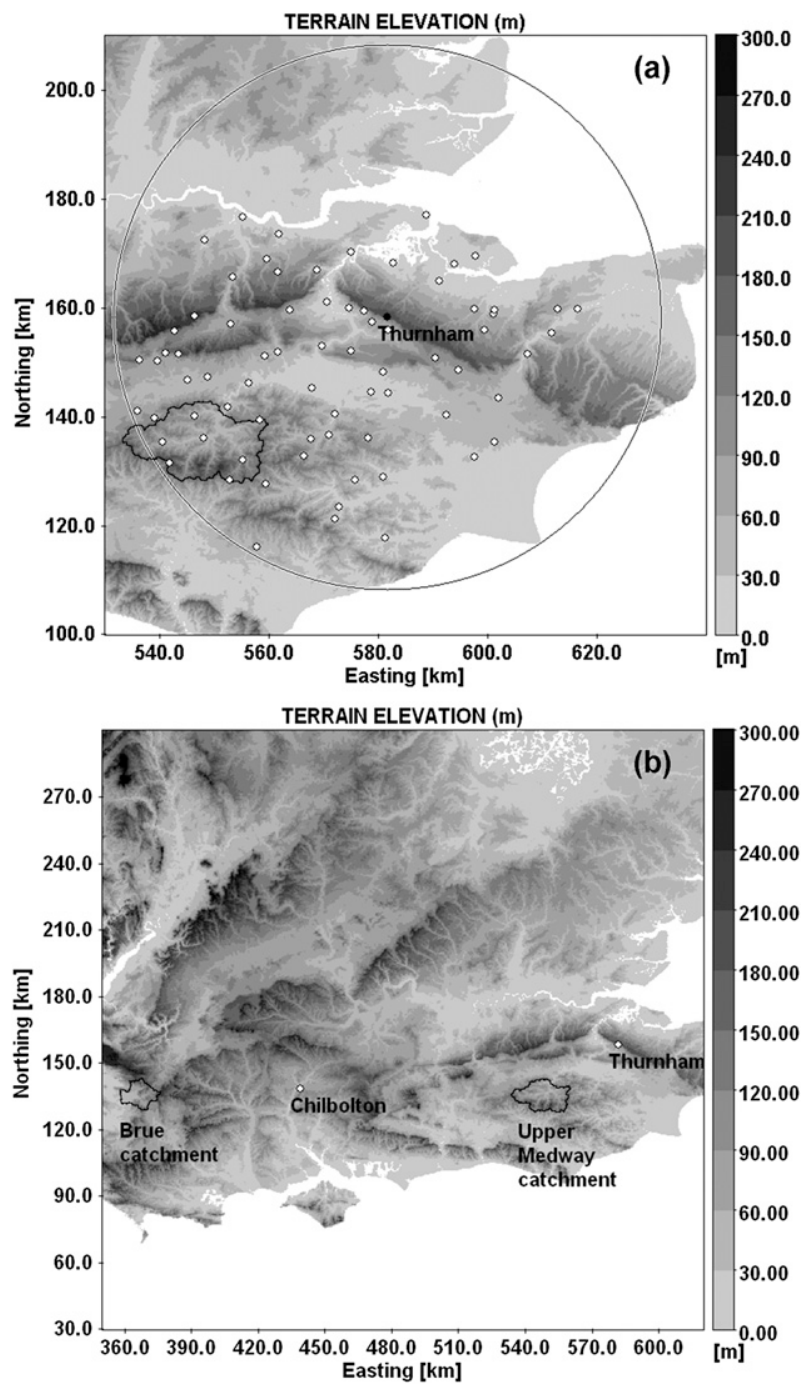

FIG. 1. (a) Location of the Met Office C-band operational radar at Thurnham (black dot) superimposed on the digital terrain elevation map. The circled white dots show locations of the tippingbucket gauges in the south area, Kent region, operated by the U.K. Environmental Agency. The irregular marked contour centered at $[550,140 \mathrm{~km}]$ is the Upper Medway basin. The range ring is at $50 \mathrm{~km}$. (b) Locations of Chilbolton (where disdrometer data were taken from) and the Brue catchment area (where the dense gauge measurements were made during HYREX).

detail by Bringi et al. $(2006,2009)$ and hence are only summarized herein:

(i) For each range profile (or beam), a data mask was generated to separate precipitation ("meteo") from nonprecipitation ("non meteo") echoes using the standard deviation of $\Phi_{\mathrm{dp}}$ over a 10-gate moving window. The classification was based on using a threshold of $12^{\circ}$ for the Thurnham radar, which is consistent with Rico-Ramirez and Cluckie (2008, their Fig. 2). 
TABLE 1. Some key technical specifications of the Met Office's Thurnham radar.

\begin{tabular}{|c|c|}
\hline \multicolumn{2}{|l|}{ Aerial system } \\
\hline Antenna diameter & $4.27 \mathrm{~m}$ \\
\hline Beamwidth at half power & $0.95^{\circ}$ \\
\hline Polarization & $\begin{array}{l}\text { Linear } \mathrm{H} / \mathrm{V} \text { : simultaneous } \\
\text { transmission }\end{array}$ \\
\hline Scanning rate & Up to 6 RPM (typical 2-3 RPM) \\
\hline Radome type & Orange peel \\
\hline \multicolumn{2}{|l|}{ Transmitter } \\
\hline Radar frequency & $5300-5700 \mathrm{MHz}$ \\
\hline Wavelength & $5.5 \mathrm{~cm}(\mathrm{C}$ band $)$ \\
\hline Peak power & $54 \mathrm{dBW}(250 \mathrm{~kW})$ \\
\hline Pulse widths & $0.4,0.8$, and $2 \mu \mathrm{s}$ \\
\hline PRF & $250-1300 \mathrm{~Hz}$ \\
\hline \multicolumn{2}{|l|}{ Radar data } \\
\hline$Z_{\mathrm{h}}, Z_{\mathrm{dr}}, \Phi_{\mathrm{dp}}, \rho_{\mathrm{co}}$ & $\begin{array}{l}\text { First and second moments } \\
\text { of the Doppler spectrum }\end{array}$ \\
\hline $\begin{array}{l}\text { Linear depolarization ratio } \\
\quad(\text { LDR })\end{array}$ & $\begin{array}{l}\text { Available in bypass mode } \\
\text { (estimated system limit } \\
-33 \text { to }-34 \mathrm{~dB})\end{array}$ \\
\hline \multicolumn{2}{|l|}{$\begin{array}{l}\text { Location (Thurnham, Kent, } \\
\text { United Kingdom) }\end{array}$} \\
\hline Lat & $51.2942^{\circ}$ \\
\hline Lon & $0.6059^{\circ}$ \\
\hline Alt & $219 \mathrm{~m} \mathrm{MSL}$ \\
\hline
\end{tabular}

(ii) The system gain was determined from solar calibrations performed regularly by the Met Office, and the radar constant was not adjusted. It was independently verified that no adjustment was needed based on $K_{\mathrm{dp}}$ versus attenuation-corrected $Z_{h}$ scatterplots (quantified in terms of contoured $2 \mathrm{D}$ frequency of occurrence plots) in rain against scattering simulations using drop size distributions measured by the Chilbolton disdrometer (the latter is described in the next section). For an example, see Fig. 10 of Bringi et al. (2006).

(iii) The measured $Z_{h}$ was corrected for rain attenuation using the iterative ZPHI method first described in Bringi et al. (2001b). The same algorithm was subsequently used by Bringi et al. (2006, 2009). The standard ZPHI algorithm is described in Testud et al. (2000).

(iv) To derive $K_{\mathrm{dp}}$, we first use the iterative range filter methodology applied to each range profile of $\Phi_{\mathrm{dp}}$. The finite impulse response (FIR) range filter is, in essence, a weighted moving average filter where the weights are determined by the desired magnitude response of the filter transfer function (or spectrum). Here, the FIR filter coefficients are based on 300-m gate spacing [an example of the filter transfer function for $150-\mathrm{m}$ gate spacing can be found in Hubbert and Bringi (1995)]. The iterative nature of the algorithm described in Hubbert and Bringi (1995) is designed to remove local perturbations in the $\Phi_{\mathrm{dp}}$ data (e.g., due to backscatter differential phase) while still preserving the propagation phase data. A "telescoping" method is used to compute the $K_{\mathrm{dp}}$ from the iteratively filtered $\Phi_{\mathrm{dp}}$ profile: that is, a variable number of gates are used, depending on the $Z_{h}$ value, to determine the slope of a linear least squares fit (10 gates if $Z_{h}>45 \mathrm{dBZ} ; 20$ gates if $35<Z_{h}<45 \mathrm{dBZ}$; and 30 gates if $Z_{h}<30 \mathrm{~dB} Z$ ). The telescoping method is as such ad hoc but generally corresponds to the "light" (9 gates) and "heavy" (25 gates) filtering for computing $K_{\mathrm{dp}}$ by Ryzhkov et al. (2005a): their gate spacing of $267 \mathrm{~m}$ is comparable to the Thurnham radar. The standard deviation of the estimate of $K_{\mathrm{dp}}$ in rain was determined from the processing described above to be $\approx 0.3^{\circ} \mathrm{km}^{-1}$ for the Thurnham radar.

(v) The measured $Z_{\mathrm{dr}}$ was corrected for rain attenuation using the method of Tan et al. (1995). The latter is a gate-by-gate correction method based on the nonlinear relation between differential attenuation and $K_{\mathrm{dp}}$ at $\mathrm{C}$ band of the form $A_{\mathrm{dp}}=\alpha K_{\mathrm{dp}}^{\beta}$ (Jameson 1992). In the next section, we show that $\alpha=0.0107$ and $\beta=1.35$ from disdrometer simulations.

(vi) The $Z_{\mathrm{dr}}$ system bias was determined by examining scatterplots (again quantified in terms of contoured, $2 \mathrm{D}$ frequency of occurrence plots) of corrected $Z_{\mathrm{dr}}$ versus corrected $Z_{h}$ in rain and noting how closely the mean value of $Z_{\mathrm{dr}}$ with $Z_{h}$ corresponds with scattering simulations from measured DSDs. An offset was applied to the $Z_{\mathrm{dr}}$ data to force the mean $Z_{\mathrm{dr}}$ versus $Z_{h}$ variation to closely follow the scattering simulations [the method and example are given in Fig. 10 of Bringi et al. (2006)]. The $Z_{\mathrm{dr}}$ offsets determined in this manner were not found to always be in agreement with the vertical pointing data (when it was raining at the radar site) but were usually within $0.5 \mathrm{~dB}$. Because we used the $0.7^{\circ}$ elevation angle scans in the rain retrievals, it was judged that the $Z_{\mathrm{dr}}$ offsets based on the lowelevation scan data in rain would be more appropriate. One caveat is that the radome does affect the measured $Z_{\mathrm{dr}}$ more or less periodically with azimuth angle by about $\pm 0.2 \mathrm{~dB}$ (because of the periodicity of the panel seams with eight panels, for the low-elevation angles; Sugier and Tabary 2006). However, the system bias for the events analyzed in this paper was quite stable at $-1 \mathrm{~dB}$ from 28 June through 24 July 2007.

(vii) The attenuation-corrected and bias-adjusted $Z_{\mathrm{dr}}$ was filtered in range using the same FIR filter described earlier. This reduced the large gate-to-gate 


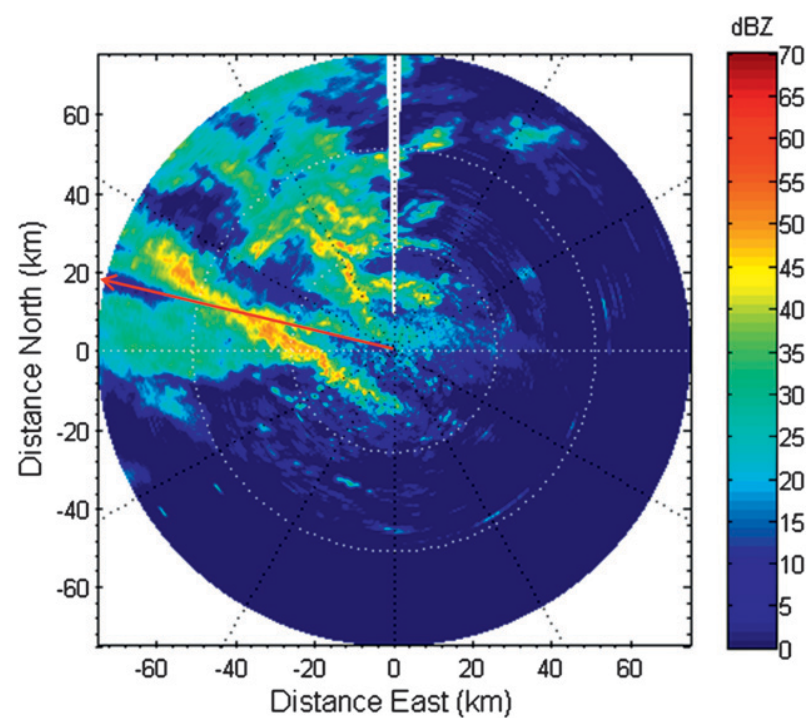

FIG. 2. PPI scan of reflectivity data, taken at 1043 UTC $20 \mathrm{Jul}$ 2007. The red arrow shows the azimuth along which the range profiles given in Fig. 3 were taken.

fluctuations alluded to earlier to a more reasonable standard deviation estimate of $\sim 0.5 \mathrm{~dB}$.

To illustrate the radar data processing steps listed above, Fig. 2 shows a PPI scan data of measured $Z_{h}$ followed by six panels of range profiles in Figs. $3 \mathrm{a}-\mathrm{f}$ along the azimuth marked in by a red arrow in Fig. 2. These data are from 1043 UTC 20 July 2007 [see also Thompson et al. (2008), who analyzed this particular event]. The rainfall was intense from this squall line and produced local flooding in several areas.

Figure 3a shows the range profile of measured $Z_{h}$ along with the $Z_{h}$ corrected for attenuation using the iterative ZPHI method referred to above in the third item. At $120 \mathrm{~km}$, the path attenuation is about $25 \mathrm{~dB}$ and the differential propagation phase $\Phi_{\mathrm{dp}}$ is $220^{\circ}$ (see Fig. 3d). Figure $3 \mathrm{~b}$ shows the measured and attenuationcorrected $Z_{\mathrm{dr}}$ (the fifth item): the path differential attenuation is nearly $7 \mathrm{~dB}$ for corresponding $\Phi_{\mathrm{dp}}$ increase of $220^{\circ}$. Figure $3 \mathrm{c}$ shows the FIR-filtered $Z_{\mathrm{dr}}$ (the seventh item), which removes the very rapid gate-to-gate fluctuations while still retaining the physical variability. Figure $3 \mathrm{~d}$ shows the measured $\Phi_{\mathrm{dp}}$ along with the iteratively filtered $\Phi_{\mathrm{dp}}$. Figure $3 \mathrm{e}$ shows the $K_{\mathrm{dp}}$ calculated from the filtered $\Phi_{\mathrm{dp}}$ as described above in the fourth item. The peak $K_{\mathrm{dp}}$ along this beam reaches $5.5^{\circ} \mathrm{km}^{-1}$. In this same panel, the data mask referred to in the first item above is also shown (meteo $=1$ and non-meteo $=$ $0)$. Finally, in Fig. 3f, the rain rate estimated from what is later termed the composite algorithm is shown (see section $2 \mathrm{~b}$ and the appendix for details). The peak rain rate reaches $100 \mathrm{~mm} \mathrm{~h}^{-1}$ along this beam: later it will be shown that the total rain accumulation from this storm reached up to $80 \mathrm{~mm}$ in some areas.

\section{b. Drop size distribution measurements}

The attenuation correction algorithms as well as the various rain retrieval algorithms were developed on the basis of DSD measurements from an impact-type disdrometer (RD-80; Joss and Waldvogel 1967) located in southern England, more precisely in Chilbolton, Hampshire (Fig. 1b). The assumption here is that the characteristics derived from these DSD measurements are equally representative of rainfall within the Thurnham radar coverage in southeast England. The accuracy of the Joss disdrometer DSD measurements has been evaluated, for example, by Sheppard and Joe (1994) and Williams et al. (2000).

Three months of disdrometer data during the summer season of 2007 were used for the present study. A total of 8816 of 1-min-averaged DSDs were fitted to a normalized gamma distribution with parameters $N_{w}, D_{0}$, and $\mu$, using the procedure given in Bringi et al. (2003). The range and mode of the parameter values were $N_{w}[1000$ $10000]$ with mode at $6300 \mathrm{~mm}^{-1} \mathrm{~m}^{-3}, D_{0}[0.6-2.0]$ with mode at $1.3 \mathrm{~mm}$, and $\mu$ [ -2 to 6$]$ with mode at 0 . The output of the fitting procedure was then used as input to T-matrix scattering calculations to determine the various relationships required for the C-band algorithms.

The scattering calculations were performed with the following assumptions: (i) drop shapes based on the most recent $80-\mathrm{m}$ fall bridge experiments [Eq. (1) of Thurai et al. (2007) for $D>1.5 \mathrm{~mm}$ and the Beard and Kubesh (1991) fit for $0.7<D<1.5 \mathrm{~mm}$, as given in Eq. (3) of Thurai et al. (2007)]; (ii) Gaussian canting angle distribution with mean of $0^{\circ}$ and standard deviation of $7.5^{\circ}$, again based on the $80-\mathrm{m}$ fall bridge experiment (Huang et al. 2008); (iii) upper integration diameter of $3.0 D_{0}$ or $8 \mathrm{~mm}$, whichever is less; and (iv) temperature of $20^{\circ} \mathrm{C}$ and elevation angle of $0^{\circ}$. (The elevation angle dependence between $0^{\circ}$ and $0.7^{\circ}$ is negligible, with the latter being the elevation angle of the Thurnham radar observations used herein for gauge comparisons.) The T-matrix scattering program outputs, for each fitted DSD (with parameters $N_{w}, D_{0}$, and $\mu$ ), the values of $Z_{h}, Z_{\mathrm{dr}}, K_{\mathrm{dp}}$, specific attenuation $A_{h}$, and specific differential attenuation $A_{\mathrm{dp}}$.

For attenuation correction of the measured $Z_{h}$, we need the relation between $A_{h}$ and $K_{\mathrm{dp}}$. This is shown in Fig. 4a based on scattering simulations described above. The best-fit power law is also shown. The linearity is excellent and the multiplicative coefficient lies in the range quoted in the literature as summarized by Carey et al. (2000). The linearity also justifies the use of the iterative ZPHI method (Bringi et al. 2001b), which 

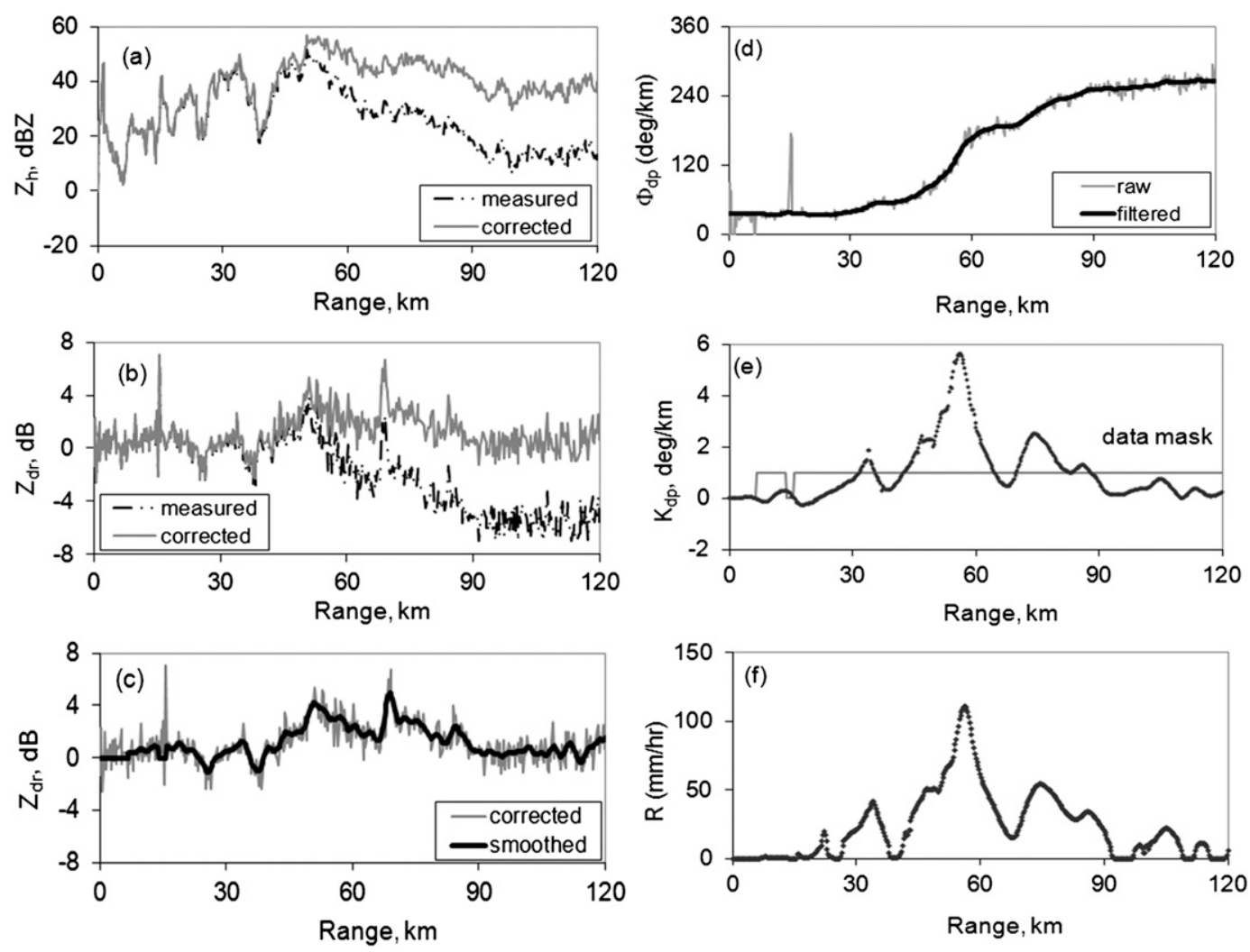

FIG. 3. Range profiles along the red arrow in Fig. 2 of (a) measured and attenuation-corrected reflectivity, (b) measured and attenuation-corrected differential reflectivity, (c) attenuation-corrected and the filtered/smoothed differential reflectivity, (d) measured and the FIR-filtered differential phase, (e) specific differential phase with the data mask, and (f) the estimated rainfall rate using the composite algorithm RC. The radar beam azimuth is $287^{\circ}$.

enables the adjustment of the coefficient on a beam-bybeam basis, with the default value being $0.069 \mathrm{~dB}$ per degree.

For attenuation correction of the measured $Z_{\mathrm{dr}}$, the $A_{\mathrm{dp}}-K_{\mathrm{dp}}$ relation is derived using a nonlinear least squares fit to arrive at $A_{\mathrm{dp}}=0.0107 K_{\mathrm{dp}}^{1.35}$. Figure $4 \mathrm{~b}$ shows the scatterplot of $A_{\mathrm{dp}}-K_{\mathrm{dp}}$ determined from the 1-min DSD data for the three summer months. Although there is considerable scatter in the calculations due to DSD variation, the fitted line seems a good representation of the mean variation. A simple gate-to-gate correction scheme was used to determine the corrected $Z_{\mathrm{dr}}$ range profiles following the procedure in Tan et al. (1995).

For rain-rate estimation, three different estimators have been used to evaluate the most suitable algorithm. The estimators, all based on the scattering calculations using the 1-min DSD data, are as follows: (i) the bestfitted $Z_{h}-R$, (ii) the best-fitted $R-K_{\mathrm{dp}}$, and (iii) combination of (i) and (ii) as well as the best-fitted $R\left(Z_{h}, Z_{\mathrm{dr}}\right)$. Henceforth, for notational simplicity, the subscript $h$ will be dropped (i.e., $Z_{h} \equiv Z$ ).
The first two algorithms are relatively straightforward. Figures 5a,b show their scatterplots: namely, $R$ versus $Z$ and $R$ versus $K_{\mathrm{dp}}$, respectively. In each case, the bestfitted equation is also given. For the former, the relationship $Z=244 R^{1.59}$ is obtained, which is close to the Marshall-Palmer DSD-based relationship given by $Z=$ $200 R^{1.6}$. When inverted, the disdrometer-based $Z-R$ relationship, gives rise to

$$
R(Z)=0.0317 Z_{\text {linear }}^{0.628}
$$

For the second estimator, the best-fitted equation

$$
R\left(K_{\mathrm{dp}}\right)=24.68 K_{\mathrm{dp}}^{0.81}
$$

is used, which is not too different from the corresponding relationship derived by Bringi et al. (2006) using 2D video disdrometer measurements from Okinawa, Japan, given by $R=28.8 K_{\mathrm{dp}}^{0.85}$. Note that the multiplicative coefficient can be sensitive to the $\mathrm{D}_{0}$ distribution of the local DSD climatology. Similar to Ryzhkov et al. (2005a), Eq. (2) is 

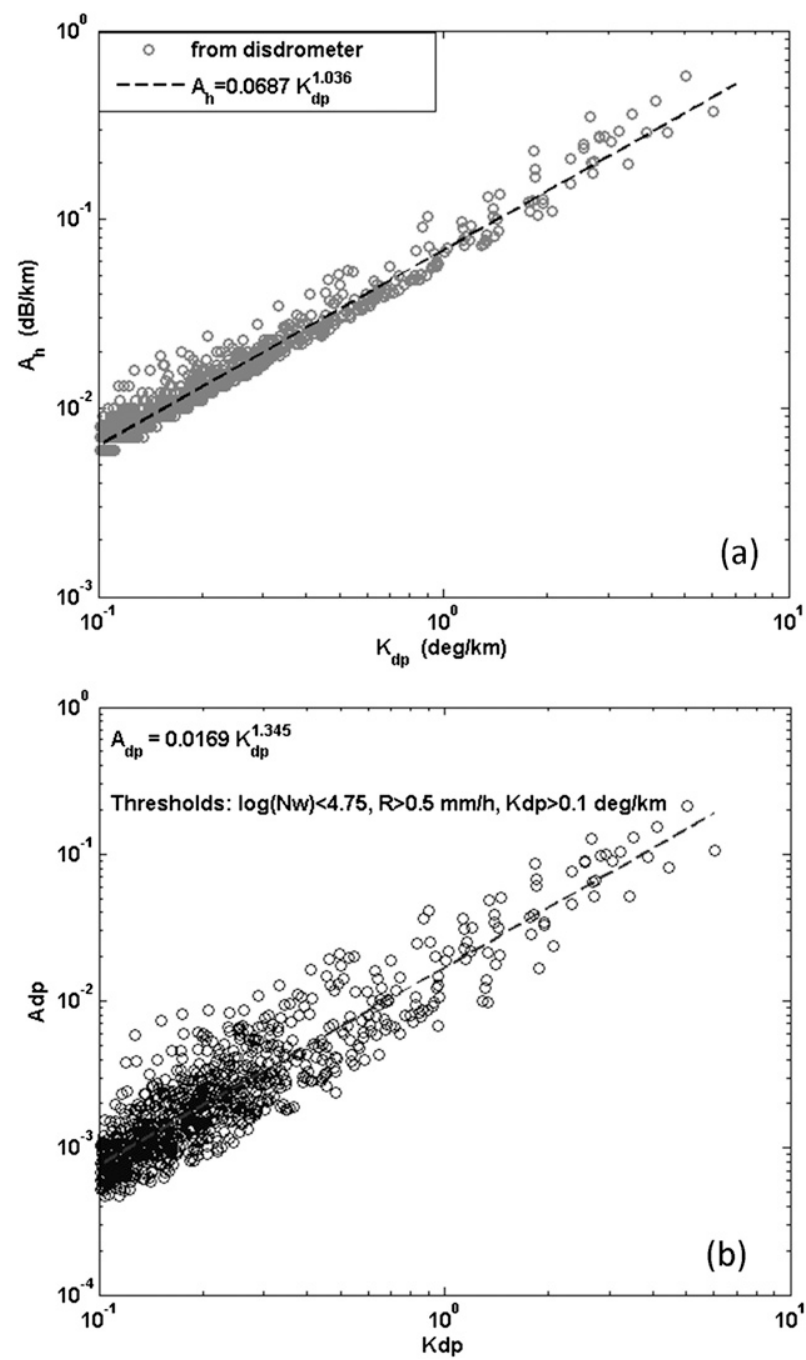

FIG. 4. Scatterplot of (a) $A_{h}$ vs $K_{\mathrm{dp}}$ and (b) $A_{\mathrm{dp}}$ vs $K_{\mathrm{dp}}$ derived from the C-band scattering simulations using the disdrometer dataset for June, July, and August 2007, taken in southern England.

modified by $\operatorname{sgn}\left(K_{\mathrm{dp}}\right)$ to obtain an unbiased estimate of rainfall amounts when $K_{\mathrm{dp}} \approx 0$ and noisy.

The third rain-rate estimator is based on a variant of the approach described by Ryzhkov et al. (2005a) but adapted for $\mathrm{C}$ band and using the scattering simulations alluded to earlier. The synthetic or the composite algorithm uses $R(Z), R\left(K_{\mathrm{dp}}\right)$, or $R\left(Z, Z_{\mathrm{dr}}\right)$, depending on various threshold conditions, given in the flowchart in Fig. 2 of Bringi et al. (2009) (also summarized in the appendix of this paper $)$. The $R\left(Z, Z_{\mathrm{dr}}\right)$ component of the composite algorithm is given by (again determined from the same disdrometer dataset)

$$
R\left(Z, Z_{\mathrm{dr}}\right)=0.0121 Z_{(\text {linear })}^{0.822} Z_{\mathrm{dr}(\text { (ratio) }}^{-1.7486}
$$
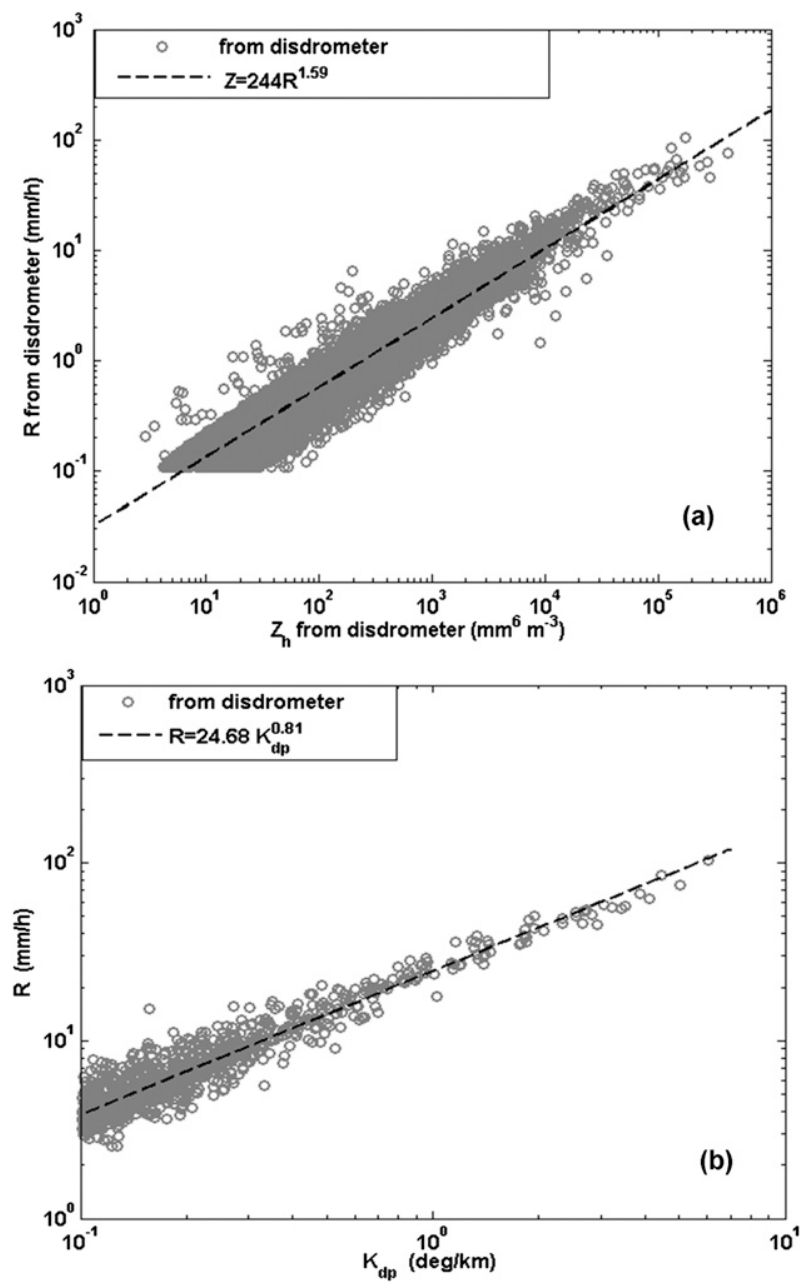

FIG. 5. Scatterplot of (a) $R$ vs $Z_{h}$ and (b) $R$ vs $K_{\text {dp }}$, both based on scattering simulations using same disdrometer dataset as used in Fig. 4.

The flowchart in the appendix summarizes the threshold conditions where each of the rain-rate equations [Eqs. (1)-(3)] are used. The thresholds for $K_{\mathrm{dp}}$ and $Z_{\mathrm{dr}}$ were based on considering the standard deviations of these measureables by using FIR range-filtered data in homogeneous (uniform reflectivity) regions of rain.

Figures $6 \mathrm{a}-\mathrm{c}$ show the scatterplots of the retrieved $R$ using the three estimators versus the disdrometer-measured $R$. The figures are given in order to illustrate the performance of the algorithms under ideal conditions with the scatter about the 1:1 line reflecting the parameterization (or algorithm) error.

The scatterplots given in Figs. 6a-c enable us to quantify the errors arising from the application of the various algorithms. Such an "algorithm error" is a measure of the variability of the individual DSD-based calculations from the mean fits given in Eqs. (1)-(3). In the following, we will denote 

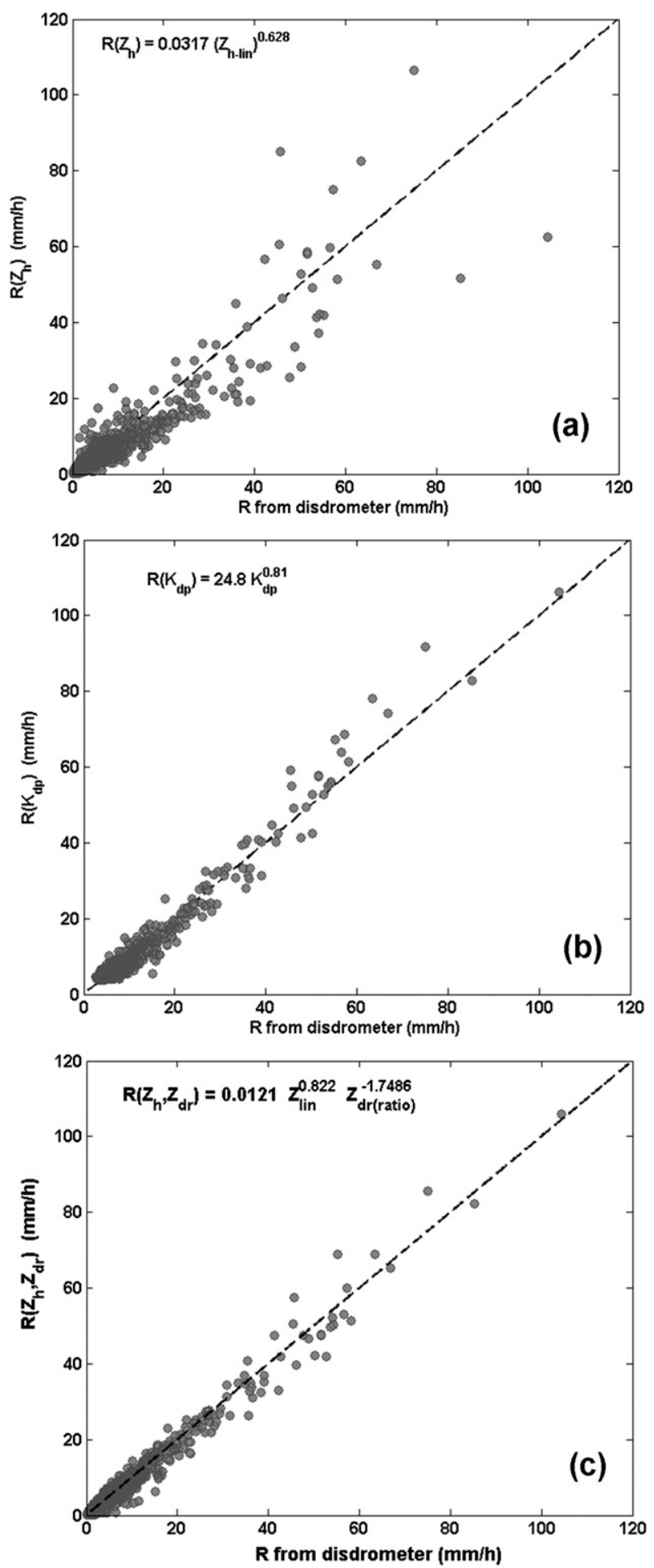

FIG. 6. Scatterplot of $R$ retrieved from (a) $Z_{h}$ [using Eq. (1)]; (b) $K_{\mathrm{dp}}$ [using Eq. (2)]; and (c) $Z_{h}, Z_{\mathrm{dr}}$, and $K_{\mathrm{dp}}$ [using Eq. (3)] vs the direct $R$ from the disdrometer for the same disdrometer dataset as used in Fig. 4. The calculations use the disdrometer DSDs and drop shape assumption and canting angle distribution as described in the text.
TABLE 2. The FSE for the different rain-rate estimators based on disdrometer data. The thresholds are $R>0.2,1,3$, and $6 \mathrm{~mm} \mathrm{~h}^{-1}$.

\begin{tabular}{cccc}
\hline $\begin{array}{c}\text { Rain-rate threshold } \\
\left(\mathrm{mm} \mathrm{h}^{-1}\right)\end{array}$ & Algorithm & $\sigma_{\delta}\left(\mathrm{mm} \mathrm{h}^{-1}\right)$ & FSE (\%) \\
\hline 0.2 & & & \\
& R1 & 1.3 & 52.8 \\
& RC & 0.93 & 33 \\
& RK & 1.0 & 35.9 \\
1 & & & \\
& R1 & 1.72 & 42 \\
& RC & 1.25 & 26.3 \\
& RK & 1.36 & 28.6 \\
3 & & & \\
& R1 & 3.7 & 34 \\
& RC & 1.72 & 21.5 \\
& RK & 1.9 & 23.8 \\
6 & & & \\
& R1 & 5.3 & 27.6 \\
& RC & 2.35 & 17.4 \\
& RK & 2.7 & 20.0 \\
\hline
\end{tabular}

(i) algorithm $\mathrm{R} 1$ from $Z=200 R^{1.6}$;

(ii) algorithm RK given by Eq. (2);

(iii) the composite algorithm $\mathrm{RC}$ given by the flowchart in the appendix; and

(iv) an additional algorithm $\mathrm{R} 2$ from $Z=200 R^{1.6}$, but without the radar measured $Z$ being corrected for attenuation.

Table 2 gives the fractional standard error (FSE; in \%) of the three algorithms for four cases: namely, when the rain-rate threshold (determined from disdrometer data) exceeds (i) 0.2 , (ii) 1 , (iii) 3 , and (iv) $6 \mathrm{~mm} \mathrm{~h}^{-1}$. The FSE is defined as

$$
\mathrm{FSE}=\frac{\sigma_{\delta}}{\left\langle R_{\text {disdro }}\right\rangle},
$$

where $\delta=R_{\text {est. }}-R_{\text {disdro }}, \sigma$ is the standard deviation of $\delta$, and $\langle\cdot\rangle$ denotes the sample mean. The term $R_{\text {est. }}$ can be any one of the four algorithms listed above, and $R_{\text {disdro }}$ is the true rain rate as measured by the disdrometer. In Table 2, the FSE for R2 will be the same as those for R1. Note that the FSE for RC is based on only $R\left(Z, Z_{\mathrm{dr}}\right)$ (i.e., without compositing). Included in the table are the $\sigma_{\delta}$ values in $\mathrm{mm} \mathrm{h}^{-1}$ for the various thresholds and algorithms.

In general, it is seen that higher thresholds result in lower FSE. Additionally, we note that RC has the lowest FSE for all four cases of rain-rate thresholds. The values given in the table, in particular the values corresponding to RC, will be used later in section $3 \mathrm{c}$ on error analysis. For the higher thresholds, the FSE of RK is close to that of RC. The RK estimator has the practical advantages of not requiring absolute calibration of the radar and being immune to signal attenuation. 


\section{c. Point-to-area variance}

It has been recognized that, when comparing radar rainfall estimates with rain gauge measurements, part of the differences should be attributed to the fact that rain gauges provide point measurements, whereas radar rainfall estimates represent a larger volume in space. As a result, representativeness errors arise because of the differences between the two very different sample volumes (Kitchen and Blackall 1992). Ciach and Krajewski (1999) proposed a methodology to estimate the variance of the differences between radar $\left(R_{r}\right)$ and rain gauge $\left(R_{g}\right)$ as follows:

$$
\begin{aligned}
\operatorname{var}\left(R_{r}-R_{g}\right)= & \operatorname{var}\left[\left(R_{r}-R_{a}\right)-\left(R_{g}-R_{a}\right)\right] \text { and } \\
\operatorname{var}\left(R_{r}-R_{g}\right)= & \operatorname{var}\left(R_{r}-R_{a}\right)-2 \operatorname{cov}\left(R_{r}-R_{a}, R_{g}-R_{a}\right) \\
& +\operatorname{var}\left(R_{g}-R_{a}\right),
\end{aligned}
$$

where $\operatorname{var}(\cdot)$ and $\operatorname{cov}(\cdot)$ represent the variance and covariance of random variables, respectively, and $R_{a}$ represents the true area-averaged rainfall. Assuming that the differences between radar and the true rainfall and that the differences between a rain gauge and the true rainfall are uncorrelated, the covariance term can be neglected. Therefore, the variance between the radar and the true area-averaged rainfall becomes

$$
\operatorname{var}\left(R_{r}-R_{a}\right)=\operatorname{var}\left(R_{r}-R_{g}\right)-\operatorname{var}\left(R_{g}-R_{a}\right) .
$$

The last term of Eq. (6) is known as the point-to-area variance, and it is attributed to the gauge representativeness error (GRE). This can be expressed as

$\operatorname{var}\left(R_{g}-R_{a}\right)=\operatorname{var}\left(R_{g}\right)-2 \operatorname{cov}\left(R_{g}, R_{a}\right)+\operatorname{var}\left(R_{a}\right)$,

which in turn can be rewritten as (see Ciach and Krajewski 1999)

$$
\begin{aligned}
\operatorname{var}\left(R_{g}-R_{a}\right)= & \operatorname{var}\left(R_{g}\right)\left[1-\frac{2}{A} \int_{A} \rho\left(x_{g}, x\right) d x^{2}\right. \\
& \left.+\frac{1}{A^{2}} \int_{A} \int_{A} \rho(x, y) d x^{2} d y^{2}\right]
\end{aligned}
$$

where $\operatorname{var}\left(R_{g}\right)$ is the variance of the point gauge measurement, $A$ is the areal domain of the radar pixel with $x-y$ coordinates, $\rho(\cdot, \cdot)$ is the spatial correlation, and $x_{g}$ is the location of the gauge within the radar pixel. Equation (8) can be used to define the variance reduction factor (VRF) given by (Habib and Krajewski 2002)

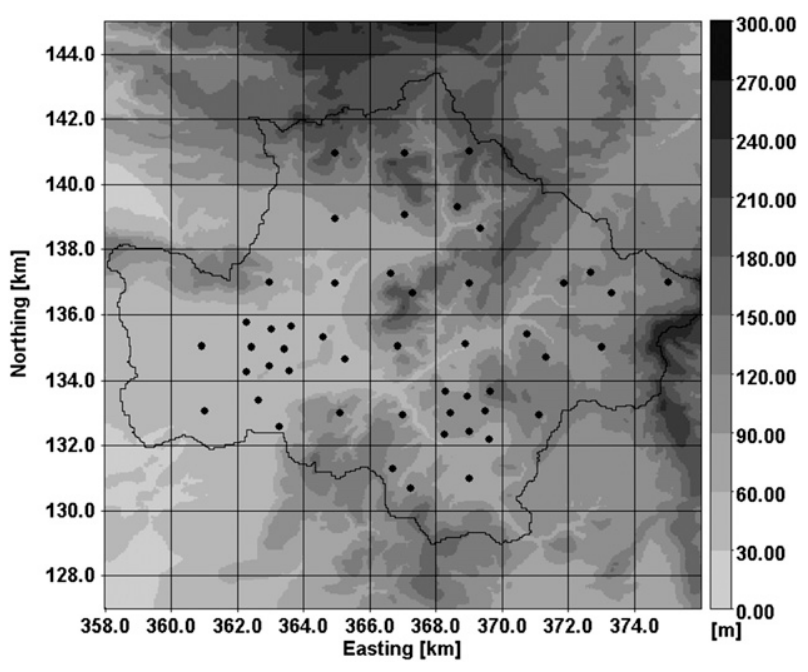

FIG. 7. Map of the rain gauge network and the Brue catchment during HYREX.

$$
\begin{aligned}
\operatorname{VRF} & =\frac{\operatorname{var}\left(R_{g}-R_{a}\right)}{\operatorname{var}\left(R_{g}\right)} \\
& =1-\frac{2}{A} \int_{A} \rho\left(x_{g}, x\right) d x^{2}+\frac{1}{A^{2}} \int_{A} \int_{A} \rho(x, y) d x^{2} d y^{2}
\end{aligned}
$$

There are two ways to calculate VRF: (i) by having a superdense cluster of gauges inside a typical radar pixel and estimating directly $\operatorname{var}\left(R_{g}-R_{a}\right)$ as in Wood et al. (2000) and (ii) by using the spatial correlation function in Eq. (9). Most prior work (e.g., Habib and Krajewski 2002, and references therein) has used Eq. (9) to compute VRF because, for example, it allows for application to various sized radar pixels. Moreover, it can be generalized to include multiple gauges within different sized pixels (e.g., Moore et al. 2000).

In this paper, the VRF will be calculated using both methods. To achieve this, a unique dataset was used from the HYREX conducted in the United Kingdom (Moore et al. 2000), in which a dense network of 49 tipping-bucket gauges (TBRs) with a resolution of $0.2 \mathrm{~mm}$ was located within the Brue catchment $\left(135 \mathrm{~km}^{2}\right)$ area in the southwest of England (shown in Fig. 1b). The gauge network was arranged in such a way that it included two superdense clusters with 8 gauges each within a $4 \mathrm{~km}^{2}$ area, representing a typical radar pixel (see Fig. 7). This dataset covers the months from October 1993 to October 1997.

The quality control of gauge data is of primary importance for this type of analysis. Typical errors include gauge malfunctioning, blockages, and timing errors. To identify problematic gauges and periods, the 49 gauges within the Brue catchment were accumulated over 24-h 

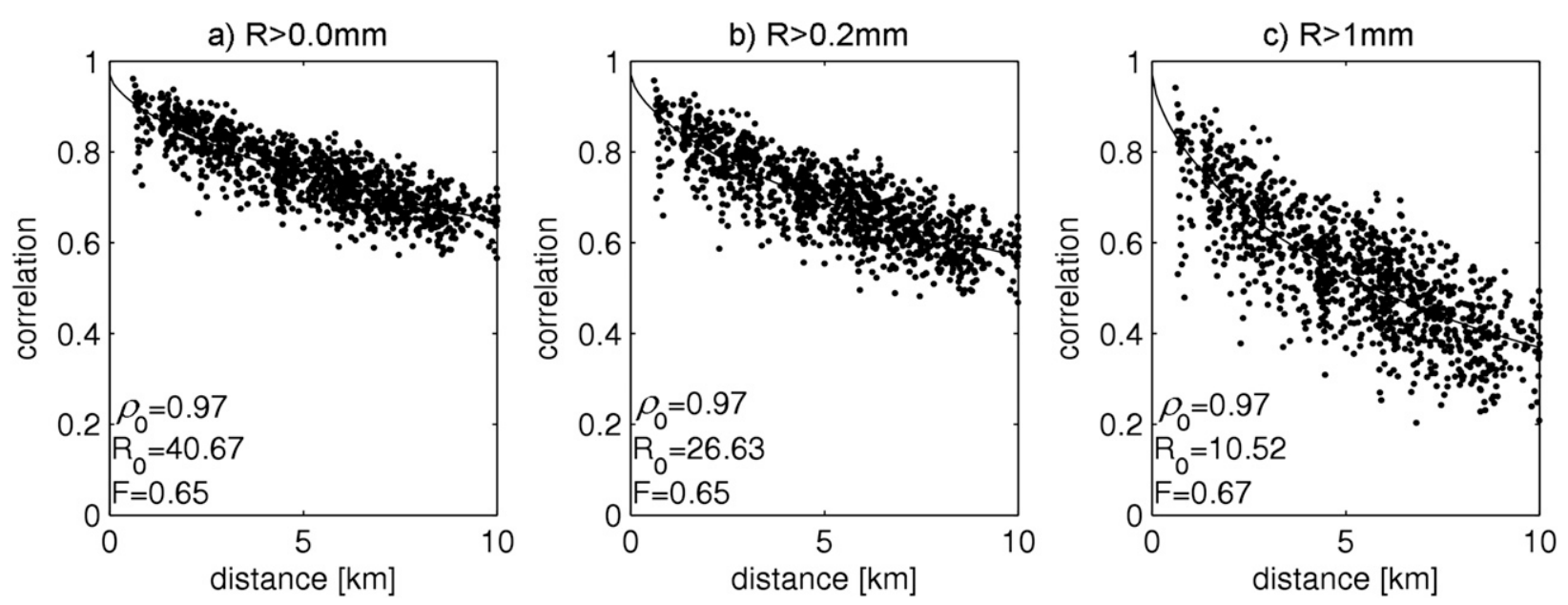

FIG. 8. Spatial correlation functions for different rainfall thresholds using 60-min accumulations.

periods. The 24-h gauge accumulations were compared against each other and those accumulations lying outside the $10 \%$ and $90 \%$ quantiles were discarded from the analysis.

The correlation function was calculated using the Pearson correlation coefficient, and it was also assumed that the spatial correlation is isotropic. For the representation of the spatial correlation function, a three-parameter exponential model is used (Habib and Krajewski 2002),

$$
\rho(d)=\rho_{0} \exp \left[-\left(d / R_{0}\right)^{F}\right]
$$

where $d$ represents the separation distance, $R_{0}$ is the correlation radius, $F$ is the shape parameter, and $\rho_{0}$ is the nugget parameter. An accurate estimation of $\rho_{0}$ will require collocated gauges, which were not available in this dataset. According to Krajewski et al. (2003), $\rho_{0}$ represents the decorrelation due to microscale variability or random instrumental errors (and also rainfall climate regime dependent), and it is in the range of 0.95-0.97. Villarini et al. (2008) analyzed the time dependency of the nugget parameter and showed that the value of $\rho_{0}$ is 0.96 for the 5-min scales and tends to be within 0.95-0.99 for larger time scales.

To avoid any problem with the fitting of the nugget parameter, we have used a default value of 0.97 in all our calculations, which is the same as that used by MTL. A nonlinear least squares algorithm was applied to fit the spatially correlated data to Eq. (10) for different rainfall thresholds assuming 60-min accumulations. The results are shown in Figs. $8 \mathrm{a}-\mathrm{c}$. It is clear from these results that there is more scatter for higher rainfall thresholds. The correlation radius $R_{0}$ also tends to decrease with rainfall threshold. It is also interesting to see that the shape parameter $F$ is around 0.65 for all rain thresholds but tends to increase to about 0.85 for thresholds larger than $3 \mathrm{~mm}$ (with $R_{0}=2.79 \mathrm{~km}$; not shown). Villarini et al. (2008) carried out a similar analysis with the HYREX dataset and showed that the spatial correlation increases with accumulation time, and they found that the parameters $\left[\rho_{0}, R_{0}, F\right]$ of the spatial correlation function were $[0.98,37.3,0.91]$ for 60 -min accumulations, which is in close agreement with the results shown in Fig. 8a.

Figure 9a shows the 60-min accumulation scatterplot between the point rainfall from each gauge within the superdense cluster and the true area-averaged rainfall. The two superdense gauge clusters used herein were shown earlier in Fig. 7 with an area of $4 \mathrm{~km}^{2}$ each. To calculate the true area-averaged rainfall, at least six valid gauges were available for a particular time period; otherwise, that record was removed from the analysis. Although there were some 60-min gauge accumulations with rainfall above $20 \mathrm{~mm}$, most of the rainfall was below $10 \mathrm{~mm}$. As shown, even within such a small area, there is a lot of scatter between the true rain and the point rainfall.

Figure $9 \mathrm{~b}$ shows the point-to-area variance $\operatorname{var}\left(R_{g}-R_{a}\right)$ as a function of the true area-averaged rainfall $R_{a}$. As shown, the point-to-area variance tends to increase with the true area-averaged rainfall. Wood et al. (2000) carried out an analysis using the HYREX dataset and found that the point-to-area variance for 15-min rainfall thresholds of 1 and $8 \mathrm{~mm}$ were approximately 0.16 and $4 \mathrm{~mm}^{2}$, respectively. The variances shown in Fig. 9 are much smaller than Wood et al.'s results because we are using longer accumulation periods (60 $\mathrm{min})$.

Figure 10a shows the point-to-area variance against rainfall threshold, whereas Fig. 10b shows the VRF against rainfall threshold. Again, these are for 60-min 
a)

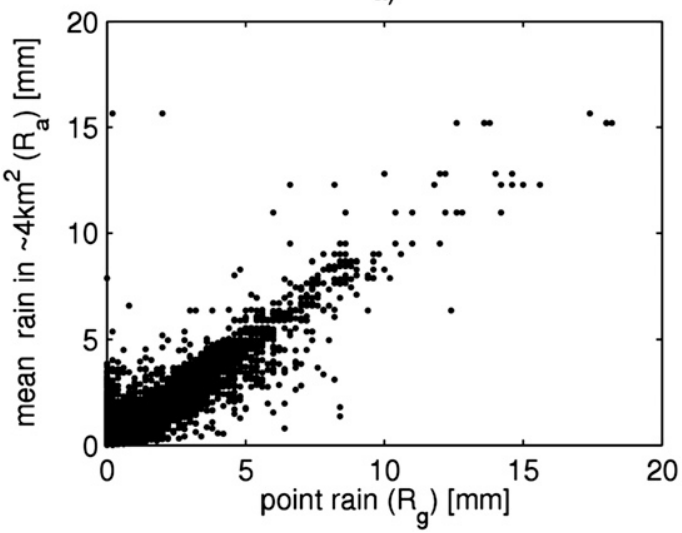

b)

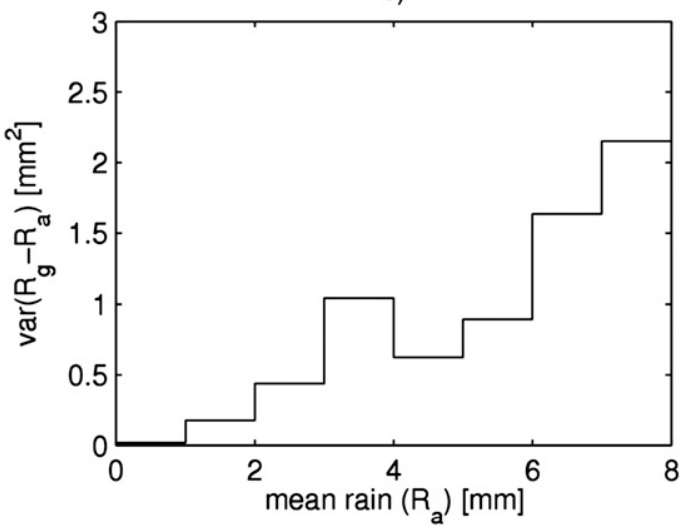

FIG. 9. (a) Scatterplot between the true area-averaged rainfall $R_{a}$ vs point gauge $R_{g}$ rainfall from each gauge in the superdense cluster and (b) gauge representativeness error $\operatorname{var}\left(R_{g}-R_{a}\right)$ vs mean areal rainfall $R_{a}$ within a $4 \mathrm{~km}^{2}$ area using 60-min accumulations.

accumulations. These results represent the gauge representativeness errors that will be used in section $3 \mathrm{c}$ to explain part of the errors when comparing radar rainfall estimates with gauge measurements. The VRF is $13 \%$, $20 \%, 29 \%$, and $43 \%$ for rain thresholds of $0.2,1,3$, and $6 \mathrm{~mm}$, respectively, and the corresponding variances from Fig. 10a are 0.16, 0.41, 1.6, and $5.1 \mathrm{~mm}^{2}$.

An independent way to verify these results was performed using the spatial correlation functions shown in Fig. 8 in Eq. (9). The pixel was assumed to be $4 \mathrm{~km}^{2}$, and the gauge was located at the center and at the corner of that pixel to show the VRF extremes. The results are also shown as crosses in Fig. 10b, which bound the VRF curve obtained using the direct method based on the data from the superdense gauge clusters. The excellent agreement between the two methods gives confidence when we apply it to the error variance separation in section $3 \mathrm{c}$.

\section{Radar-gauge comparisons \\ a. Summary of events and gauge data}

The precipitation events selected for our analysis cover two periods, period 1 from 28 June to 4 July 2007 and period 2 from 19 to 24 July 2007. During both periods the precipitation was mostly convective, typical of summertime rainfall in southeast England. However, the 20 July 2007 event during period 2 was particularly intense, causing local flooding in London and several other areas in the United Kingdom. This event was analyzed from the viewpoint of attenuation correction of a)

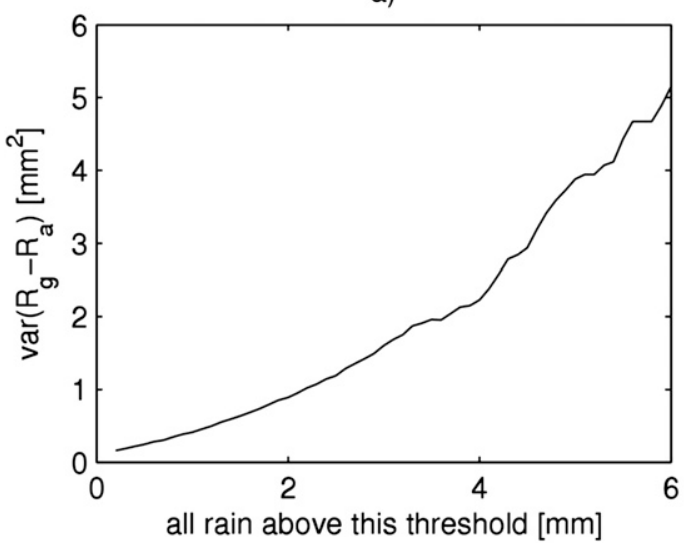

b)

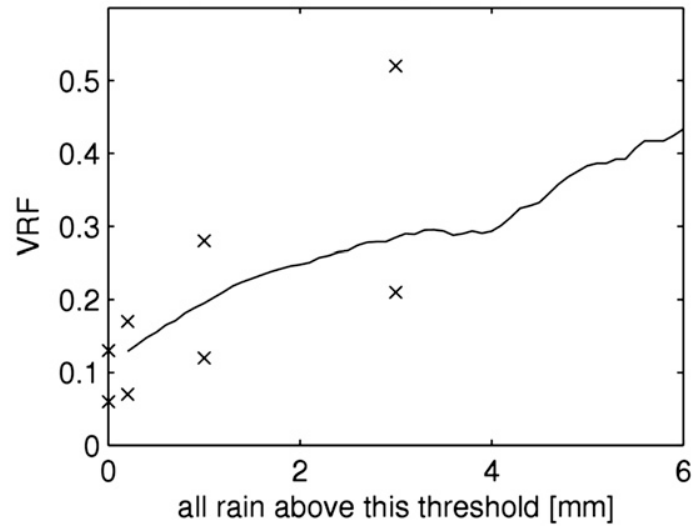

FIG. 10. (a) Point-to-area variance and (b) VRF as a function rainfall threshold. The crosses represent the results of using Eq. (9), with the lower crosses corresponding to the gauge location at the center of the $2 \mathrm{~km} \times 2 \mathrm{~km}$ pixel and the upper crosses to gauge location at the corner of the pixel. 


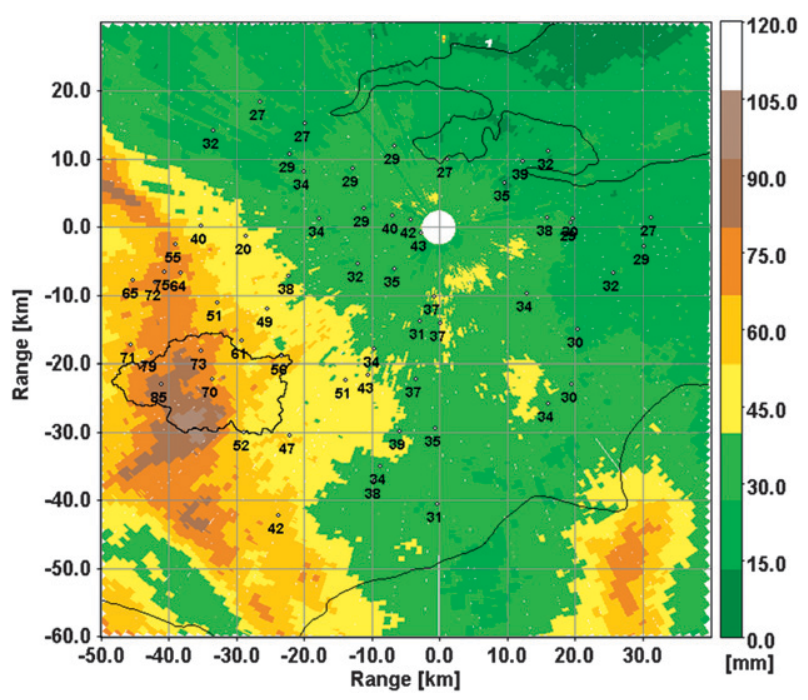

FIG. 11. Total rain accumulation for the 19-24 Jul 2007 event, determined from the $\mathrm{RC}$ algorithm using Thurnham radar data, together with the rain accumulations from the rain gauges located in southern region, Kent area, United Kingdom.

the measured $Z_{h}$ as well as comparison of rain amounts with gauges by Thompson et al. (2008).

The 73 gauges in southeast Kent (Fig. 1) are of the tipping-bucket type with $0.2 \mathrm{~mm}$ per tip. The base data are the times of each tip, which are converted to 5-min rain accumulations $\left(12 \mathrm{~h}^{-1}\right.$ starting at 0000 UTC each day) to coincide with radar sampling times, which are every 5 min starting at 0000 UTC. The 5 -min gauge accumulations were visually examined for each of the 73 gauges for each day of the two periods, giving confidence that the gauge data were quality controlled to a high degree (as opposed to using automatic quality control methods).

Figure 11 shows the radar-based total rainfall accumulation map for period 2 along with gauge totals (in $\mathrm{mm}$ ) to illustrate the spatial rain patterns as well as to give a subjective sense of the point rainfall amounts relative to "areal" radar-based amounts. Note that, in this figure, the composite RC algorithm (see section $2 \mathrm{~b}$ ) was used for the radar-based accumulation. Data from the second PPI sweep at elevation angle of $0.7^{\circ}$ was chosen for the radar estimates.

The gauge located at $[-40,-22 \mathrm{~km}]$ recorded the maximum accumulation of $85 \mathrm{~mm}$ for period 2 (with most occurring between approximately 0900 and 1100 UTC 20 July 2007). The radar-based accumulation map is also remarkably free of artifacts arising from ground clutter and beam blockages (see also Fig. 1 for the terrain map near the radar site). For period 2, the maximum gauge accumulation was $68 \mathrm{~mm}$ (radar-based accumulation map is not shown).

\section{b. Comparisons}

For the radar-gauge comparisons, we have combined periods 1 and 2 to compare radar-based hourly rainfall accumulation over each of the gauge locations. Because the radar-based rain-rate estimates are available at each pixel $\left(1^{\circ} \times 250 \mathrm{~m}\right)$ every $5 \mathrm{~min}$, one would not expect the hourly accumulation to be subject to significant temporal representativeness error (Kitchen and Blackall 1992). However, for fast moving, highly convective rain cells, Fabry et al. (1994) and Austin et al. (2010), using high-resolution radar data to simulate the temporal representativeness error, have shown that this error can be as much as $20 \%$ for 5 -min sampling. Other factors such as vertical variability of rain rate may also contribute to the error in the radar-gauge comparisons but are not considered here, because past studies on the height variation of radar reflectivity profiles (Hall and Goddard 1978) have shown the vertical variation to be uniform, at least on a statistical basis for ranges $<60 \mathrm{~km}$.

For the spatial averaging over the location of each gauge, a polar area of $3^{\circ} \times 750 \mathrm{~m}$ was chosen. The averaging is based on rain rates at 9 pixels surrounding the gauge, with equal weighting. Because the radar data from the three beams (azimuthal spacing being $1^{\circ}$ ) are independent, the measurement errors of $Z_{h}, Z_{\mathrm{dr}}$, and $K_{\mathrm{dp}}$ will be reduced by the factor $1 / \sqrt{3}$. Along the beam, the estimates at the three consecutive gates (gate spacing being $250 \mathrm{~m}$ ) are correlated because of smoothing in range so that a further reduction in measurement error is expected to be negligible.

Figure 12 shows the scatterplot of hourly rainfall amounts from the radar-based estimators versus the gauge amounts in two panels. The top panel compares [RC, R1] against gauges, and the bottom panel compares $[\mathrm{R} 2, \mathrm{RK}]$. The minimum hourly amount from gauges is $0.2 \mathrm{~mm}$ corresponding to 1 tip in $1 \mathrm{~h}$, and this threshold has been used in the scatterplots. Visual inspection of these plots illustrates the following:

- The RC estimates, for hourly amounts $>5 \mathrm{~mm}$, show higher correlation and very little bias compared with R1 and R2 estimators (i.e., the best accuracy overall).

- The RK estimates, as expected, show very large scatter at low rainfall $(<5 \mathrm{~mm})$, whereas at higher thresholds the correlation and bias improve considerably.

- The R1 estimator (based on $Z=200 R^{1.6}$ ) with $Z$ corrected for attenuation performs quite well at lower rainfall $(<5 \mathrm{~mm})$. The performance is acceptable at higher amounts, especially considering that an a priori fixed (i.e., not tuned) $Z-R$ relation is used.

- The R2 estimator, which is the R1 estimator without attenuation correction, is seriously biased (underestimate) for rainfall $>5 \mathrm{~mm}$, again as expected, and 

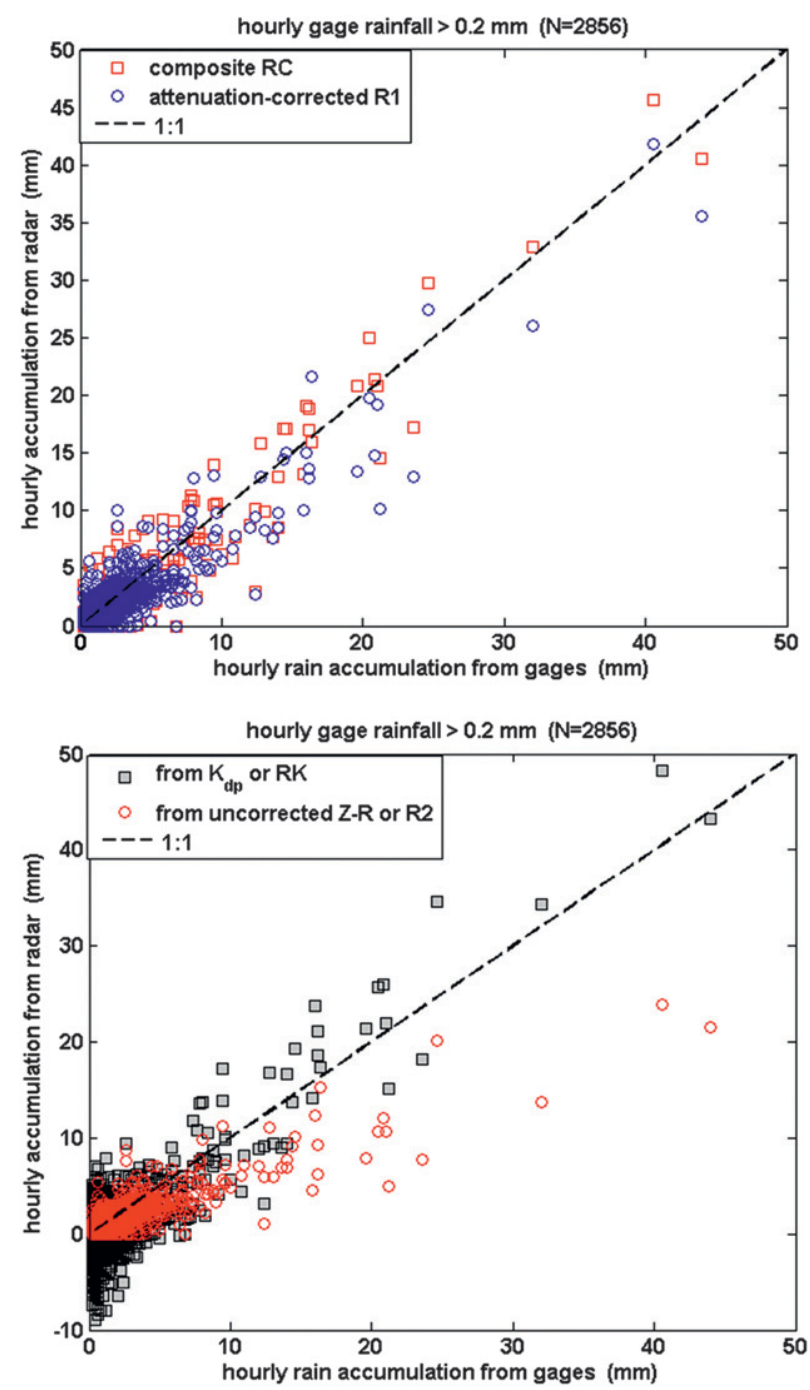

FIG. 12. Estimates of hourly accumulations from the radar data using (top) R1 and RC algorithms and (bottom) RK and R2 algorithms, both compared with the hourly accumulation from gauges.

pointing to the importance of attenuation correction of the measured $Z$ in convective rain at $\mathrm{C}$ band.

Table 3 shows some key statistics of the radar-gauge comparisons for four thresholds (i.e., gauge hourly amounts $>0.2,1,3$, and $6 \mathrm{~mm}$ ), along with the number of samples used in computing the statistics. Because the number of samples is not sufficiently large, we are unable to show the statistics conditioned by intervals of rainfall amounts. The table shows the values for the Pearson correlation coefficient $r$, the Nash and Sutcliffe (1970) model efficiency coefficient (Nash), the mean absolute error (MAE), and the fractional bias (bias). These parameters are defined as follows $(R$ is the
TABLE 3. Key statistics of the radar-gauge comparisons for four thresholds, along with the number of samples used in computing the statistics.

\begin{tabular}{|c|c|c|c|c|c|}
\hline $\begin{array}{c}\text { Gauge } \\
\text { hourly }>0.2 \mathrm{~mm}\end{array}$ & Algorithm & $r$ & Nash & $\begin{array}{l}\text { MAE } \\
(\%)\end{array}$ & $\begin{array}{l}\text { Bias } \\
(\%)\end{array}$ \\
\hline \multicolumn{6}{|l|}{ No. of samples $=2856$} \\
\hline & $\mathrm{R} 2$ & 0.87 & 0.68 & 43.4 & -26.3 \\
\hline & $\mathrm{R} 1$ & 0.91 & 0.82 & 39 & -13.8 \\
\hline & $\mathrm{RC}$ & 0.93 & 0.85 & 38.3 & -12.4 \\
\hline & RK & 0.75 & 0.21 & 114.2 & -50.2 \\
\hline \multirow{2}{*}{\multicolumn{6}{|c|}{$\begin{array}{l}\text { Threshold of } 1 \mathrm{~mm} \\
\text { No. of samples }=1138\end{array}$}} \\
\hline & & & & & \\
\hline & $\mathrm{R} 2$ & 0.85 & 0.59 & 40.2 & -30.8 \\
\hline & R1 & 0.9 & 0.79 & 33.9 & -17.7 \\
\hline & $\mathrm{RC}$ & 0.92 & 0.83 & 32.9 & -13.3 \\
\hline & RK & 0.86 & 0.47 & 65.3 & -41.8 \\
\hline \multirow{2}{*}{\multicolumn{6}{|c|}{$\begin{array}{l}\text { Threshold of } 3 \mathrm{~mm} \\
\text { No. of samples }=303\end{array}$}} \\
\hline & & & & & \\
\hline & $\mathrm{R} 2$ & 0.84 & 0.45 & 42.2 & -38.4 \\
\hline & $\mathrm{R} 1$ & 0.91 & 0.76 & 31.8 & -22.7 \\
\hline & $\mathrm{RC}$ & 0.93 & 0.82 & 28.1 & -14 \\
\hline & RK & 0.92 & 0.65 & 42.5 & -26.2 \\
\hline \multirow{2}{*}{\multicolumn{6}{|c|}{$\begin{array}{l}\text { Threshold of } 6 \mathrm{~mm} \\
\text { No. of samples }=76\end{array}$}} \\
\hline & & & & & \\
\hline & $\mathrm{R} 2$ & 0.84 & 0.15 & 45.7 & -44.8 \\
\hline & $\mathrm{R} 1$ & 0.91 & 0.69 & 29 & -22.7 \\
\hline & $\mathrm{RC}$ & 0.93 & 0.8 & 23.7 & -10.1 \\
\hline & RK & 0.92 & 0.68 & 30.4 & -8.3 \\
\hline
\end{tabular}

radar-based hourly accumulation ${ }^{1}$ and $G$ is the gauge hourly accumulation):

$$
\operatorname{Nash}=1-\frac{\operatorname{sum}(R-G)^{2}}{\operatorname{sum}(G-\bar{G})^{2}}
$$

where "sum" means $\sum(\cdot)$ and $\overline{\mathrm{G}}$ is the mean gauge value. The Nash coefficient is usually used to assess the performance of hydrological models, but in our case it applies to the radar-based rain-rate model (see section $2 b$ ). It is also a measure of scatter of data about the 1:1 line in Fig. 12,

$$
\text { Fractional bias }=\operatorname{mean}(R-G) \div \operatorname{mean}(G) \text {. }
$$

Let $\Delta=R-G$. The MAE is defined as

$$
\operatorname{MAE}=\operatorname{mean}(|\Delta|) \div \operatorname{mean}(G) .
$$

The notation "mean" above implies the usual average over the $N$ samples: that is, $(1 / N) \Sigma(\cdot)$.

Note the Nash coefficient and the MAE may be considered to be the robust statistical parameters as compared

\footnotetext{
${ }^{1}$ The term $R$ can be $\mathrm{R} 1, \mathrm{R} 2, \mathrm{RC}$, or RK and is the same as $R_{r}$ in section $2 \mathrm{c}$, and $G$ is the same as $R_{\mathrm{g}}$.
} 
to the Pearson correlation coefficient or the root-meansquare, because the former measures are less susceptible to outliers. From Table 3, the Nash coefficient and MAE for the composite RC estimator consistently outperform the other estimators at any threshold. Recall that the composite $\mathrm{RC}$ is based on using $Z-R,\left(Z, Z_{\mathrm{dr}}\right)$, or $\left(K_{\mathrm{dp}}\right)$, as described in section $2 b$.

The second best estimator is R1, which shows the importance of correcting for rain attenuation before applying the $Z-R$ relation, especially for the stronger convective rainfall. Here, a fixed $Z=200 R^{1.6}$ relation is used following the Met Office (Harrison et al. 2000, 2009), but without any gauge adjustment. It is rather surprising that a fixed $Z-R$ relation performs so well in the two periods considered here (dominated by convective rainfall). The RK estimator shows the lowest bias for the threshold $>6 \mathrm{~mm}$, which again is not an unexpected result considering that estimation of $K_{\mathrm{dp}}$ is more accurate at higher rain rates.

The R2 estimator shows considerable bias (underestimation) for hourly thresholds $>1 \mathrm{~mm}$. Again, this is an expected result, because attenuation correction is not performed prior to applying the $Z=200 R^{1.6}$ relation.

\section{c. Error variance separation}

The concept of gauge representativeness error was brought out by Kitchen and Blackall (1992) and further developed in a formal manner by Ciach and Krajewski (1999). There are numerous references to the application of their methodology (e.g., Gebremichael and Krajewski 2004, and references therein). Within the context of dualpolarized radar rain estimators and gauge comparisons, the work of MTL is most relevant to our analysis.

As elaborated in section 2c, it is of importance to consider how much of the variance between radar and gauge is due to the point-to-area variance and how much is due to other radar-related errors such as the parameterization (or algorithm error), measurement error, etc. The variance values for the algorithm and point-to-area were evaluated previously in sections $2 b$ and $2 c$ for the hourly rainfall thresholds used herein (gauge hourly amounts $>$ $0.2,1,3$, and $6 \mathrm{~mm}$ ). Note that the point-to-area variance values from section $2 \mathrm{c}$ were obtained from the HYREX dataset, which covered period October 1993 through October 1997. Our hypothesis is that the climatology of summertime convective rain in the southern United Kingdom is not expected to change the point-to-area variance estimates from year to year. It would seem reasonable to apply these results to the radar-gauge comparisons performed in the two periods (June-July 2007) mentioned in section $3 \mathrm{a}$ and as given above in section $3 \mathrm{~b}$.

First, consider the point-to-area variance [hereafter abbreviated as $\operatorname{var}(\mathrm{p}$-to-a)] relative to the variance of

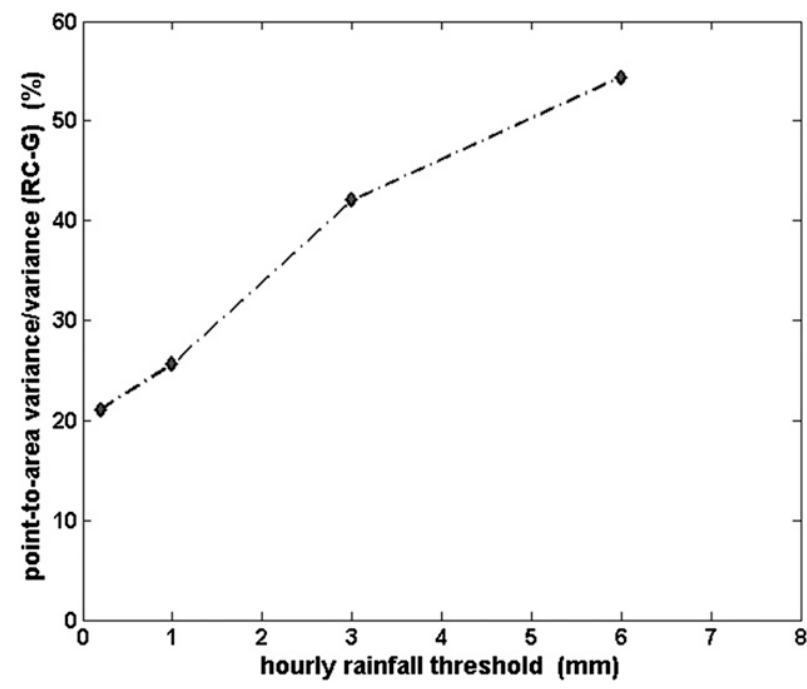

FIG. 13. Ratio of point-to-area variance to variance of $\left(\mathrm{RC}-R_{g}\right)$, where $R_{g} \equiv G$, shown for various hourly thresholds of rainfall (greater than value along the abscissa).

$\left(R_{r}-R_{g}\right)$. Following Habib and Krajewski (2002), $\operatorname{var}\left(R_{r}-R_{g}\right)$ can be expressed as [see also Eq. (6)]

$$
\operatorname{var}\left(R_{r}-R_{g}\right)=\operatorname{var}\left(R_{r}-R_{a}\right)+\operatorname{var}(\text { p-to-a }),
$$

where $R_{a}$ is the unknown true areal mean rainfall over the radar pixel and $R_{r}$ is the radar-based estimator (either R1, R2, RC, or RK): for example, the composite estimator referred to as RC. Note that one can resolve $\operatorname{var}\left(R_{r}-R_{a}\right)$ as

$$
\operatorname{var}\left(R_{r}-R_{a}\right)=\operatorname{var}\left(\varepsilon_{p}\right)+\operatorname{var}\left(\varepsilon_{m}\right)+\operatorname{var}(\varepsilon),
$$

where $\varepsilon_{p}$ is the parameterization (or algorithm) error, $\varepsilon_{m}$ is the radar measurement error, and $\varepsilon$ is the (residual) random error. All three errors are assumed to have zero mean, and further all three are assumed to be uncorrelated. Note that the underlying error model in Eq. (15) is an additive one as compared to Ciach et al. (2007), who use a multiplicative error model. Note that $\operatorname{var}\left(\varepsilon_{p}\right)$ and $\operatorname{var}\left(\varepsilon_{m}\right)$ have been dealt with in detail in Bringi and Chandrasekar (2001, chapter 8). Hereafter, $\operatorname{var}\left(R_{r}-R_{a}\right)$ will be simply referred to as radar error.

Figure 13 shows the ratio of $\operatorname{var}\left(\mathrm{p}\right.$-to-a) to $\operatorname{var}\left(\mathrm{RC}-R_{g}\right)$. It follows that the point-to-area variance is a significant component of the $\operatorname{var}\left(\mathrm{RC}-R_{g}\right)$ varying from $20 \%$ at hourly threshold of $0.2 \mathrm{~mm}$ to nearly $55 \%$ at threshold of $6 \mathrm{~mm}$.

Figure 14 shows $\operatorname{var}\left(R_{r}-R_{g}\right)$ for all four radar-based estimators versus hourly rainfall threshold; in addition, $\operatorname{var}(\mathrm{p}$-to-a) is also depicted as a bar graph (which is identical to Fig. 10a). Figure 14 clearly shows that, at low 


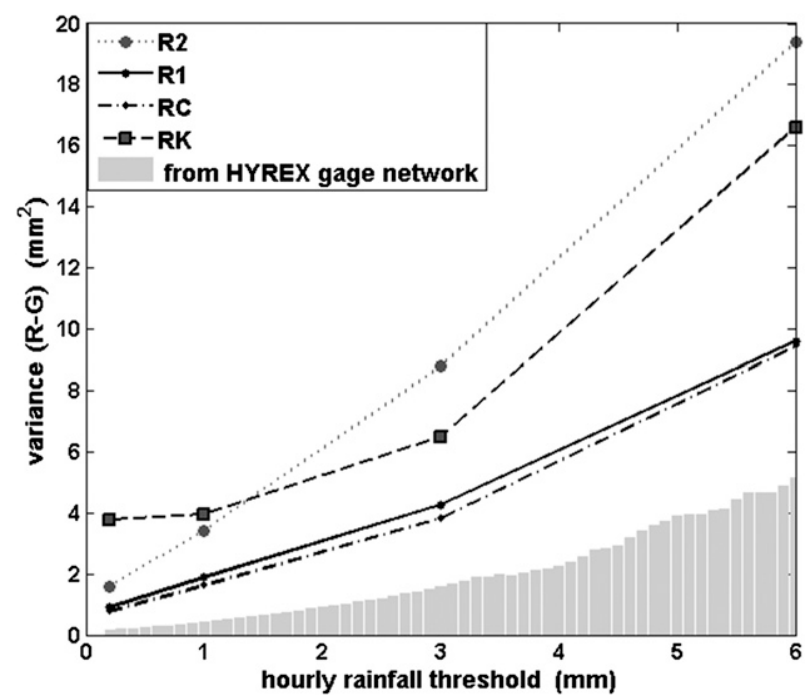

FIG. 14. The variance of $\left(R_{r}-R_{g}\right) \equiv \operatorname{var}(R-G)$ for the four algorithms used in the radar-based estimates, shown for various hourly thresholds of rainfall. The bar graph shows the point-to-area variance estimated from the HYREX data. Note that $R \equiv \mathrm{R} 2, \mathrm{R} 1$, $\mathrm{RC}$, or RK.

thresholds (i.e., likely dominated by low and thus more uniform rain rates), the proportion of $\operatorname{var}\left(R_{r}-R_{g}\right)$ that can be explained by var(p-to-a) is significantly less than when the threshold is high $(6 \mathrm{~mm})$, with the latter threshold implying more variable intense convective rainfall. Interestingly enough, the radar-based estimators $\mathrm{RC}$ and $\mathrm{R} 1$ are quite similar in terms of the proportion of variance that can be explained by $\operatorname{var}(\mathrm{p}-\mathrm{to}-\mathrm{a})$. For $\mathrm{RK}$, the proportion is much less (e.g., only $30 \%$ at threshold of $6 \mathrm{~mm}$ ).

Finally, we calculate the standard deviation of the radar error $\sigma=\sqrt{\operatorname{var}\left\{R_{r}-R_{a}\right\}}$ from Eq. (14) as

$$
\operatorname{var}\left(\mathrm{RC}-R_{a}\right)=\operatorname{var}\left(\mathrm{RC}-R_{g}\right)-\operatorname{var}(\text { p-to-a }) .
$$

Figure 15 shows the FSE $(=\sigma /\langle\mathrm{RC}\rangle)$ of the radar error (using the RC estimator) as a dashed line versus the hourly rainfall threshold from the gauges. The plot shows a decreasing trend with increasing rainfall threshold. If the hourly rainfall threshold can be used as a proxy for rain rate, then the FSE decreases with increasing rain rates (i.e., from more stratiform-like to more convective).

The bar graph in Fig. 15 shows our estimate of the FSE' of the sum of the algorithm and measurement errors,

$$
\mathrm{FSE}^{\prime}=\frac{\sqrt{\frac{1}{3} \operatorname{var}\left(\varepsilon_{m}\right)+\frac{1}{3} \operatorname{var}\left(\varepsilon_{p}\right)}}{\overline{\mathrm{RC}}} .
$$

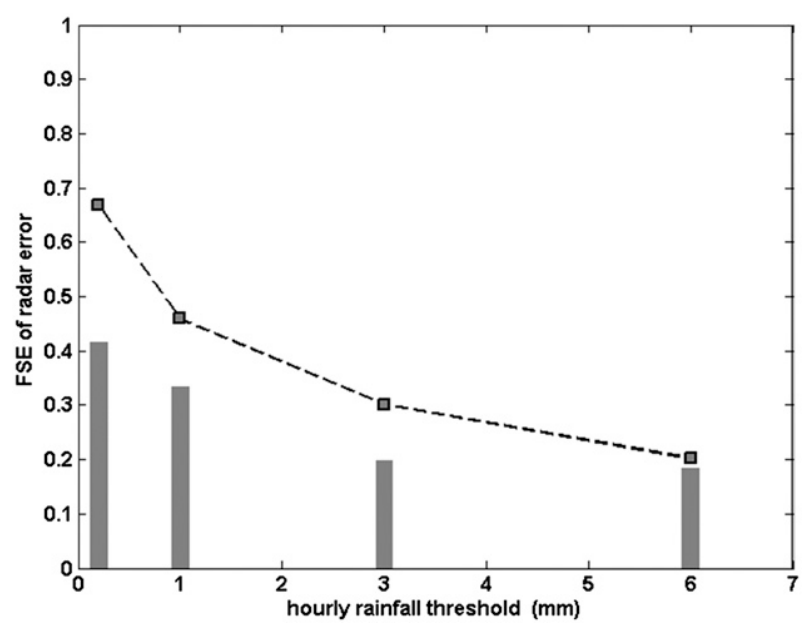

FIG. 15. Estimate of the FSE for the radar error for the RC estimator, shown (as dashed line) for various hourly thresholds of rainfall. The bar graph is $\mathrm{FSE}^{\prime}$ from Eq. (17).

To calculate the FSE', we have used the measurement error in $Z_{h}$ and $Z_{\mathrm{dr}}$ as 0.8 and $0.5 \mathrm{~dB}$, respectively. The $\operatorname{var}\left(\varepsilon_{m}\right)$ is calculated as in Bringi and Chandrasekar (2001, chapter 8$)$, whereas $\operatorname{var}\left(\varepsilon_{p}\right)$ is obtained from Table 2 . Note that the factor of 3 in Eq. (17) comes from the fact that the rain-rate estimate $(\mathrm{RC})$ is an average over $3^{\circ} \times$ $750 \mathrm{~m}$, but only the pixels from three adjacent beams are considered to be independent (see second paragraph of section 3b).

For the hourly thresholds of 0.2 and $1 \mathrm{~mm}$, we have used the $\operatorname{var}\left(\varepsilon_{m}\right)$ and $\operatorname{var}\left(\varepsilon_{p}\right)$ applicable to the $Z-R$ relation because the RC estimator would tend to use the fixed $Z-R$ relation for light rainfall in any case. At high rainfall thresholds (likely to be convective rain) $\mathrm{FSE}^{\prime}$ is $\approx 20 \%$, which is dominated by $\operatorname{var}\left(\varepsilon_{m}\right)$ [i.e., $\operatorname{var}\left(\varepsilon_{m}\right) / \operatorname{var}\left(\varepsilon_{p}+\varepsilon_{m}\right)$ is in the range $60 \%-70 \%$ ], whereas, at low thresholds of 0.2 and $1 \mathrm{~mm}$, the FSE' is dominated by $\operatorname{var}\left(\varepsilon_{p}\right)$. At the highest threshold used here $(6 \mathrm{~mm})$, FSE' accounts for nearly all of the FSE of the radar error and systematically less so as the threshold decreases.

One caveat is that $\mathrm{FSE}^{\prime}$ does not include measurement errors due to attenuation correction. Recall that $Z_{h}$ is corrected using an iterative ZPHI method, whereas $Z_{\mathrm{dr}}$ is corrected using a power law of $K_{\mathrm{dp}}$. The propagation of these errors into FSE' depends on the products $\left(A_{h} \times r\right)$ and $\left(A_{\mathrm{dp}} \times r\right)$ and $K_{\mathrm{dp}}$ along the path. The term $A_{h}\left(A_{\mathrm{dp}}\right)$ is the specific attenuation (specific differential attenuation), and $r$ is the pathlength. Following Testud et al. (2000) and Anagnostou et al. (2004), one can estimate $\operatorname{var}\left(\varepsilon_{m}\right)$ for two extreme cases where it is assumed that $A_{h} \times r=5 \mathrm{~dB}$ (i) over a path of $10 \mathrm{~km}$ (e.g., see Fig. $3 \mathrm{a}$ at ranges between 50 and $60 \mathrm{~km}$ ) and (ii) over a path of $100 \mathrm{~km}$. The estimate of $\mathrm{FSE}^{\prime}$ as in Eq. (17) only 
due to $\operatorname{var}\left(\varepsilon_{m}\right) / 3$ for the first case would be 0.21 (or 21\%). For the second case, $\operatorname{var}\left(\varepsilon_{m}\right) / 3$ would be 0.55 . These values will more than compensate for the remaining differences shown in Fig. 15 (difference between the bar graph and the dotted line).

\section{Discussion of results and comparison with related work}

One of the earliest C-band polarimetric radar-based rainfall comparisons that have been made involved the CPOL radar located in Darwin, Australia (Keenan et al. 1998). The Darwin site is well instrumented with a $D$-scale gauge network ( 21 gauges in $\sim 10 \mathrm{~km} \times 10 \mathrm{~km}$ area). For example, gauge comparisons have been made by May et al. (1999) using $R\left(K_{\mathrm{dp}}\right)$ and $Z-R$ estimators, the latter with and without attenuation correction, which in our notation is analogous to RK, R1, and R2. Although they did not specifically address the point-to-area variance, they concluded that " ... overall excellent agreement has been shown ..." when using $R\left(K_{\mathrm{dp}}\right)$ estimator. They also showed the importance of correcting for attenuation as well as beam blockage prior to using $Z-R$ relations. Their dataset included very intense tropical rain and is consistent with the excellent comparisons obtained here using RK: for example, in Fig. 12 (bottom) for mean hourly rain rates $>8 \mathrm{~mm} \mathrm{~h}^{-1}$. May et al. (1999), using disdrometer simulations from Darwin, obtained $R=$ $34.6 K_{\mathrm{dp}}^{0.83}$, with the larger coefficient being due to two factors: (i) use of a more spherical axis ratio versus $D$ relation and (ii) the statistics of the $D_{0}$ distribution in tropical rain. Their relation, if used in the U.K. summertime convection, will overestimate the $R$ for a given $K_{\text {dp }}$ [cf. Eq. (2)] by about $40 \%$.

In a subsequent study using the CPOL radar and the D-scale gauge network, Bringi et al. (2001a) used an areal rainfall estimator based on differential propagation phase (or areal $\Phi_{\mathrm{dp}}$ estimator) to compare against the mean areal gauge rainfall. They argued that, because of the high density of the gauge network, the point-to-area variance would be negligible. In addition, their measurement error variance was negligible (Ryzhkov et al. 2000, appendix). They also estimated from 10-min areal-averaged rainrate comparisons, that $25 \%$ of the radar error could be attributed to the parameterization error. Bringi et al. (2001a) also showed the importance of correcting for attenuation before applying $Z-R$ relations to estimate rainfall (without correction leads to an average underestimate of $50 \%$ relative to areal mean rainfall from gauges).

Le Bouar et al. (2001) used the CPOL radar and the $\mathrm{C}$-scale gauge network in the Darwin area (25 gauges distributed within the $150-\mathrm{km}$-radius radar umbrella as opposed to the aforementioned D-scale gauge network). Their work centered on evaluation of the ZPHI algorithm for estimating rain rate developed by Testud et al. (2000). The latter uses the derived specific attenuation at each range gate along the path together with an estimate of the generalized intercept parameter (termed $N_{0}^{*}$ by Testud et al. 2001). Their estimate of the FSE of $R$ due to $\varepsilon_{m}$ was in the range $20 \%-30 \%$. In their radar-gauge comparisons under optimal conditions (e.g., range < $60 \mathrm{~km}$; their quality index $=1$ ), they found the Pearson correlation coefficient for 30-min average $R$ using the ZPHI algorithm ( $R$ was averaged over an area of $2-\mathrm{km}$ radius around gauge site) versus 30-min gauge measured $R$ to be 0.92 . Again, it is difficult to compare with our data, but the Pearson correlation coefficient is similar to the range of values for the RC estimate in Table 3 . When they used the uncorrected $Z-R$ relation, they found that the correlation coefficient dropped to 0.87 (generally in the same range as for our R1 estimator in Table 3) and fractional bias of $-63 \%$, which is significantly higher than the range found for R1. This may be due to much higher frequency of intense convective rain in the tropics (increased attenuation) as compared to the midlatitudes.

Although Le Bouar et al. (2001) did not calculate the point-to-area variance, they were certainly aware of its importance. They refer to the results of Kitchen and Blackall (1992) and Anagnostou et al. (1999) to estimate the point-to-area variance in terms of $\operatorname{var}[\log (R / G)]$. In logarithmic terms, they estimated that the point-to-area variance could account for $70 \%$ of the variance of the ZPHI estimator, for hourly accumulations and $4 \mathrm{~km} \times$ $4 \mathrm{~km}$ pixel size. Le Bouar et al. (2001) do comment that their estimates " ... should be considered as a theoretical limit ..." Notwithstanding the differences between $\operatorname{var}(R-G)$ and $\operatorname{var}[\log (R / G)]$, compared with Fig. 13, the proportion of $70 \%$ greatly exceeds what is estimated here at maximum of $55 \%$ for hourly gauge accumulations $>6 \mathrm{~mm}$.

More recently, MTL compared the ZPHI method at $\mathrm{X}$ band with a dense gauge network (25 gauges) at short ranges $(<25 \mathrm{~km})$. Their error variance separation and estimate of radar error were made for hourly accumulations over a $1 \mathrm{~km} \times 1 \mathrm{~km}$ pixel over a year. The number of samples with mean hourly gauge rain rate $>0.2 \mathrm{~mm} \mathrm{~h}^{-1}$ was nearly 3500 , whereas for $>1 \mathrm{~mm} \mathrm{~h}^{-1}$ it was around 1000 (see Table 3, which shows comparable number of samples for similar thresholds). Hence, some of our results can be compared with theirs (though it must be kept in mind that their radar was operating at $\mathrm{X}$ band as opposed to $\mathrm{C}$ band).

From MTL, overall (i.e., for gauge hourly amounts $>$ $0.2 \mathrm{~mm}$ ), the ZPHI method gave a Nash coefficient of 
0.84 and $10 \%$ bias (underestimate), which is comparable to the RC estimator values from Table 3 at similar gauge hourly threshold $(0.2 \mathrm{~mm})$ : that is, a Nash coefficient of 0.85 and bias (underestimate) of $12 \%$. This might be a fortuitously close agreement between two very different rain estimators ( $\mathrm{RC}$ and $\mathrm{ZPHI}$ ) operating at different frequency bands. However, in general, both estimators are designed to account for drop size distribution variations, though in different ways.

MTL obtained the FSE of the radar error [see Eq. (16)] using ZPHI method to vary slowly from $25 \%$ at their lowest hourly threshold $(0.2 \mathrm{~mm})$ to $20 \%$ at threshold of $2 \mathrm{~mm}$. By way of comparison, the FSE in Fig. 15 reduces more rapidly with corresponding values from $68 \%$ to $20 \%$.

MTL's estimate of gauge representativeness error, which they define as $\sqrt{\mathrm{VRF}}$ [see Eq. (9)], was close to $20 \%$, independent of hourly rainfall threshold. To arrive at the VRF, they first obtained their spatial correlation function [see Eq. (10)] from the ZPHI method (i.e., radarderived spatial correlation function for mean hourly rain rates of $>1$ and $>3 \mathrm{~mm}$ ) using 1 month of data. This function with parameters $\left[\rho_{0}, R_{0}, F\right]$ was then used in Eq. (9) over a $1 \mathrm{~km} \times 1 \mathrm{~km}$ pixel to arrive at VRF. As a comparison, their parameter values for mean hourly rain rate $>1 \mathrm{~mm} \mathrm{~h}^{-1}$ was $[1,24.85 \mathrm{~km}, 0.63]$ may be compared with the fit Fig. 8c, with the corresponding parameters being [0.97, $10.5 \mathrm{~km}, 0.67]$. Considering the totally different methods of arriving at the spatial correlation function as in MTL and from 4 yr of gauge data from HYREX, the parameter values, especially the shape parameter, which governs how the function behaves at short distances $(<2 \mathrm{~km})$, are remarkably close. This behavior at very short distances, in fact, governs VRF for small pixels $(1 \mathrm{~km} \times 1 \mathrm{~km}$ or $2 \mathrm{~km} \times 2 \mathrm{~km})$. Com-

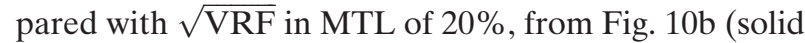
line) our $\sqrt{\mathrm{VRF}}$ values increase with hourly threshold, from $35 \%$ at $>0.2 \mathrm{~mm}$ to $50 \%$ at $>2 \mathrm{~mm}$ (MTL's mean hourly rain-rate thresholds also vary from $>0.2$ to $>2$ $\mathrm{mm} \mathrm{h}^{-1}$ ). MTL also estimated the ratio of the var(pointto-area) to the $\operatorname{var}(\mathrm{ZPHI}-G)$ in the range $30 \%-40 \%$, which may be compared with Fig. 13, where the range is $20 \%-55 \%$ when using the RC estimator.

An important conclusion reached by MTL is that the ZPHI estimate of $R$ can be used to accurately estimate the spatial correlation function if the radar can sample the rainfall areas with high spatial and temporal resolution. Our results being somewhat comparable with MTL, it can be argued that the comparably accurate $\mathrm{RC}$ estimator (for C-band radar) can also be used for similar application, which makes it possible to stratify the spatial correlation function by rain type and storm structure.

\section{Summary and conclusions}

The estimate of rainfall using an operational dualpolarized C-band radar in summertime convective storms in southeast United Kingdom (Kent) has been compared against a network of gauges. A number of preprocessing steps were carried out to ensure high radar data quality (especially for $Z_{\mathrm{dr}}$ data), system bias removal, classification of precipitation versus nonprecipitation echoes, and attenuation correction.

Four different rainfall estimators were considered: fixed $Z-R$ with and without correcting for rain attenuation; a composite estimator based on either $Z-R$, $R\left(Z, Z_{\mathrm{dr}}\right)$, or $R\left(K_{\mathrm{dp}}\right)$; and exclusively $R\left(K_{\mathrm{dp}}\right)$. The various radar rain-rate estimators were developed using Joss disdrometer data from Chilbolton, United Kingdom, from June to August 2007, in essence, sampling similar DSD characteristics as expected under the C-band radar coverage area in Kent. Scattering calculations using gamma fits to the disdrometer DSDs along with mean axis ratio and canting angle distributions were used to arrive at the power-law fits $R(Z), R\left(Z, Z_{\mathrm{dr}}\right)$, and $R\left(K_{\mathrm{dp}}\right)$. The parameterization errors of the various rain-rate estimators were also estimated.

Hourly accumulations over radar pixels (maximum range $<50 \mathrm{~km}$ ) centered on the gauge locations were compared, with about 2500 samples available for gauge hourly accumulations of $>0.2 \mathrm{~mm}$. Overall, the composite estimator performed the "best," based on robust statistical measures such as mean absolute error, the Nash-Sutcliffe coefficient, and mean bias, at all rainfall thresholds $(>0.2,>1,>3$, or $>6 \mathrm{~mm})$, with improving measures at the higher thresholds of $>3$ and $>6 \mathrm{~mm}$ (higher rain rates). The $R\left(K_{\mathrm{dp}}\right)$ estimator also performed nearly as well at the highest threshold $(>6 \mathrm{~mm})$. The fixed $Z-R$ relation (after attenuation correction) performed nearly the same as the composite estimator at the lower thresholds $(>0.2$ and $>1 \mathrm{~mm})$, but at higher thresholds ( $>3$ and $>6 \mathrm{~mm}$ ) the mean bias, mean absolute error, and Nash coefficient were all degraded relative to the composite estimator. Using a fixed $Z-R$ relation without attenuation correction, as expected, performed the "worst," with mean bias of $25 \%-45 \%$ (underestimate) and low Nash coefficients in the range 0.15-0.6.

An error variance separation was carried out by estimating the gauge representativeness error using $4 \mathrm{yr}$ of gauge data from HYREX. The proportion of variance of the radar-to-gauge differences that could be explained by the gauge representativeness errors ranged from $20 \%$ to $55 \%$ (for the composite rain-rate estimator RC). The radar error variance [defined in Eq. (16)], or the equivalent fractional standard error, was found to decrease 
from nearly $70 \%$ at the lower rain thresholds $(>0.2$ and $>1 \mathrm{~mm}$ ) to $20 \%$ at the higher rain thresholds ( $>3$ and $>6 \mathrm{~mm}$ ). It was also estimated that the sum of the parameterization and measurement errors could account for much of the radar error at the higher thresholds $(>3$ and $>6 \mathrm{~mm}$ ) and decreasingly so as the threshold decreased to $>0.2$ and $>1 \mathrm{~mm}$.

In conclusion, the composite rain-rate estimator, derived from disdrometer DSD data and scattering simulations, performed as well as can be expected (for maximum range $<50 \mathrm{~km}$ ) from error variance analysis at mean hourly rain rates of $5 \mathrm{~mm} \mathrm{~h}^{-1}$ or larger with mean bias of $10 \%$ (underestimate). At lower rain rates, a "tuned" or gauge-adjusted $Z-R$ relation with attenuation correction using differential propagation phase and good data quality control in terms of preprocessing steps as outlined here is expected to be acceptable (though no such tuning was performed in this work). The good accuracy of the composite rain-rate estimator paves the way for an accurate estimation of the spatial correlation function of rainfall using radar alone stratified by storm structure and environmental factors, in agreement with MTL.

Acknowledgments. The Leverhulme Trust (reference number F00182CB) provided support for Prof. Bringi as a visiting professor in the Department of Civil Engineering at Bristol University. MT acknowledges support from the National Science Foundation via AGS-0924622. VNB also acknowledges partial support from the NASA PMM science program via Grant NNX10AJ11G. We thank the British Atmospheric Data Centre (BADC) and the Chilbolton radar observatory for providing the disdrometer data. We also wish to thank the Met Office and the Environment Agency for providing the Thurnham radar and rain gauge data, as well as for their continuous support.

\section{APPENDIX}

\section{The Flowchart of the Composite Algorithm (RC)}

Figure A1 summarizes the conditions where each of the rain-rate equations is used. Initially, the rain rate is estimated using the $Z-R$ relation given in Eq. (1) derived from the Joss disdrometer data for the summer season of 2007 for southern England. If this estimated rain rate exceeds $13 \mathrm{~mm} \mathrm{~h}^{-1}$, then $K_{\mathrm{dp}}$ is checked to see if it is greater than $0.15^{\circ} \mathrm{km}^{-1}$, and, if so, Eq. (2) is used for rain-rate estimation. Similarly, other branches lead to the other two rain-rate equations, depending on the various conditions specified in the figure. The thresholds

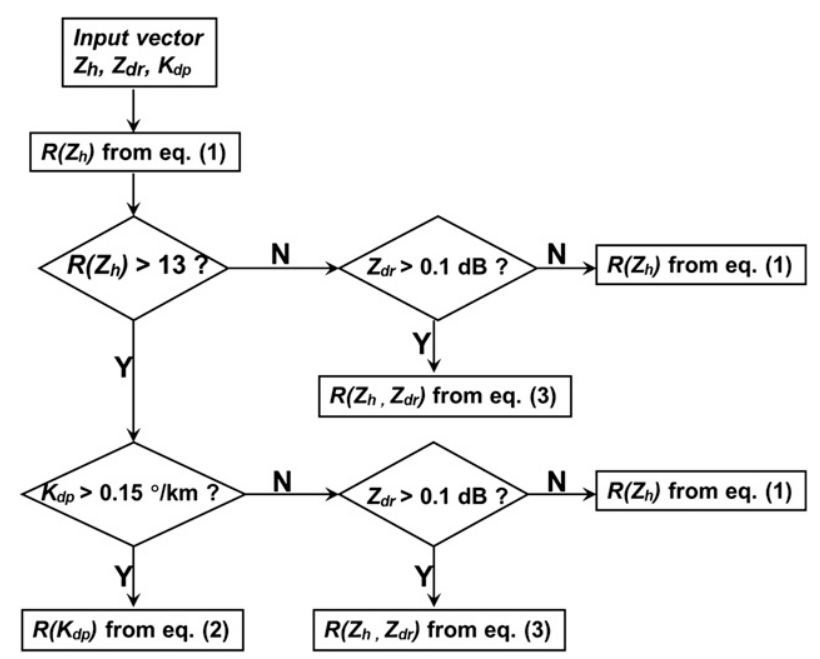

FIG. A1. Block diagram illustrating the composite algorithm RC for rain-rate estimation, together with the various values of applied thresholds.

for $K_{\mathrm{dp}}$ and $Z_{\mathrm{dr}}$ in Fig. A1 were determined considering the standard deviations of these measureables by using FIR range-filtered data in homogeneous (uniform reflectivity) regions of rain.

\section{REFERENCES}

Anagnostou, E. N., W. F. Krajewski, and J. Smith, 1999: Uncertainty quantification of mean-areal radar-rainfall estimate. J. Atmos. Oceanic Technol., 16, 206-215.

—_, M. N. Anagnostou, A. Kruger, W. F. Krajewski, and B. Miriovsky, 2004: High-resolution rainfall estimation from $\mathrm{X}$-band polarimetric radar measurements. J. Hydrometeor., 5, 106-128.

Austin, G., P. Shucksmith, and L. Sutherland-Stacey, 2010: The characterization of radar space-time sampling errors for different meteorological situations. Proc. Sixth European Conf. on Radar in Meteorology and Hydrology, Sibiu, Romania, ERAD, 3 pp.

Beard, K. V., and R. J. Kubesh, 1991: Laboratory measurements of small raindrop distortion. Part 2: Oscillation frequencies and modes. J. Atmos. Sci., 48, 2245-2264.

— , V. N. Bringi, and M. Thurai, 2010: A new understanding of raindrop shape. Atmos. Res., 97, 396-415.

Brandes, E. A., G. Zhang, and J. Vivekanandan, 2003: An evaluation of a drop distribution-based polarimetric radar rainfall estimator. J. Appl. Meteor., 42, 652-660.

Bringi, V. N., and V. Chandrasekar, 2001: Polarimetric Doppler Weather Radar: Principles and Applications. Cambridge University Press, $636 \mathrm{pp}$.

—, G.-J. Huang, V. Chandrasekar, and T. D. Keenan, 2001a: An areal rainfall estimator using differential propagation phase: Evaluation using a C-band radar and a dense gauge network in the tropics. J. Atmos. Oceanic Technol., 18, 1810-1818.

, T. D. Keenan, and V. Chandrasekar, 2001b: Correcting C-band radar reflectivity and differential reflectivity data for rain attenuation: A self-consistent method with constraints. IEEE Trans. Geosci. Remote Sens., 39, 1906-1915. 
— , V. Chandrasekar, J. Hubbert, E. Gorgucci, W. L. Randeu, and M. Schoenhuber, 2003: Raindrop size distribution in different climatic regimes from disdrometer and dual-polarized radar analysis. J. Atmos. Sci., 60, 354-365.

- M. Thurai, K. Nakagawa, G.-J. Huang, T. Kobayashi, A. Adachi, H. Hanado, and S. Sekizawa, 2006: Rainfall estimation from C-band polarimetric radar in Okinawa, Japan: Comparisons with 2D-video disdrometer and $400 \mathrm{MHz}$ wind profiler. J. Meteor. Soc. Japan, 84, 705-724.

—, C. R. Williams, M. Thurai, and P. T. May, 2009: Using dualpolarized radar and dual-frequency profiler for DSD characterization: A case study from Darwin, Australia. J. Atmos. Oceanic Technol., 26, 2107-2122.

Carey, L. D., S. A. Rutledge, D. A. Ahijevych, and T. D. Keenan, 2000: Correcting propagation effects in C-band polarimetric radar observations of tropical convection using differential propagation phase. J. Appl. Meteor., 39, 1405-1433.

Ciach, G. J., and W. F. Krajewski, 1999: On the estimation of radar rainfall error variance. Adv. Water Resour., 22, 585-595.

,,-- and G. Villarini, 2007: Product-error-driven uncertainty model for probabilistic quantitative precipitation estimation with NEXRAD data. J. Hydrometeor., 8, 1325-1347.

Diss, S., J. Testud, J. Lavabre, P. Ribstein, E. Moreau, and J. Parent du Chatelet, 2009: Ability of a dual polarized X-band radar to estimate rainfall. Adv. Water Resour., 32, 975-985.

Fabry, F., A. Bellon, M. R. Duncan, and G. L. Austin, 1994: High resolution rainfall measurements by radar for very small basins: The sampling problem reexamined. J. Hydrol., 161, 415-428.

Figueras i Ventura, J., F. Kabeche, B. Fradon, R. Hogan, A.-A. Boumahmoud, A. Illingworth, and P. Tabary, 2010: Extensive evaluation of polarimetric quantitative precipitation estimations (QPE) in ideal and less ideal conditions. Proc. Sixth European Conf. on Radar in Meteorology and Hydrology, Sibiu, Romania, ERAS, 6 pp.

Gebremichael, M., and W. F. Krajewski, 2004: Assessment of the statistical characterization of small-scale rainfall variability from radar: Analysis of TRMM ground validation datasets. J. Appl. Meteor., 43, 1180-1199.

Gorgucci, E., G. Scarchilli, and V. Chandrasekar, 1996: Error structure of radar rainfall measurement error at C-band frequencies with dual-polarization algorithm for attenuation correction. J. Geophys. Res., 101, 26 461-26 471.

Gourley, J. J., P. Tabary, and J. Parent du Chatelet, 2006: Data quality of the Meteo-France C-Band polarimetric radar. J. Atmos. Oceanic Technol., 23, 1340-1356.

,-- , and,- 2007 : A fuzzy logic algorithm for the separation of precipitating from nonprecipitating echoes using polarimetric radar observations. J. Atmos. Oceanic Technol., 24, 1439-1451.

Gu, J.-Y., A. Ryzhkov, P. Zhang, P. Neilley, M. Knight, B. Wolf, and D.-I. Lee, 2011: Polarimetric attenuation correction in heavy rain at C band. J. Appl. Meteor. Climatol., 50, 39-58.

Habib, E., and W. F. Krajewski, 2002: Uncertainty analysis of the TRMM ground-validation radar-rainfall products: Application to the TEFLUN-B field campaign. J. Appl. Meteor., 41, 558-572.

Hall, M. P. M., and J. W. F. Goddard, 1978: Variation with height of the statistics of radar reflectivity due to hydrometeors. Electron. Lett., 14, 224-225.

Harrison, D. L., S. J. Driscoll, and M. Kitchen, 2000: Improving precipitation estimates from weather radar using quality control and correction techniques. Meteor. Appl., 7, 135-144.
— R. W. Scovell, and M. Kitchen, 2009: High-resolution precipitation estimates for hydrological uses. Proc. ICE Water Manage., 162, 125-135.

Hogan, R. J., 2007: A variational scheme for retrieving rainfall rate and hail reflectivity fraction from polarization radar. J. Appl. Meteor. Climatol., 46, 1544-1564.

Huang, G.-J., V. N. Bringi, and M. Thurai, 2008: Orientation angle distributions of drops after an 80-m fall using a 2D video disdrometer. J. Atmos. Oceanic Technol., 25, 1717-1723.

Hubbert, J., and V. N. Bringi, 1995: An iterative filtering technique for the analysis of copolar differential phase and dual-frequency radar measurements. J. Atmos. Oceanic Technol., 12, 643-648.

Jameson, A. R., 1992: The effect of temperature on attenuationcorrection schemes in rain using polarization propagation differential phase shift. J. Appl. Meteor., 31, 1106-1118.

Joss, J., and A. Waldvogel, 1967: A raindrop spectrograph with automatic analysis. Pure Appl. Geophys., 68, 240-246.

Keenan, T. D., K. Glasson, F. Cummings, T. S. Bird, J. Keeler, and J. Lutz, 1998: The BMRC/NCAR C-Band Polarimetric (C-POL) radar system. J. Atmos. Oceanic Technol., 15, 871-886.

, L. D. Carey, D. S. Zrnić, and P. T. May, 2001: Sensitivity of 5-cm wavelength polarimetric radar variables to raindrop axial ratio and drop size distribution. J. Appl. Meteor., 40, 526-545.

Kitchen, M., and R. M. Blackall, 1992: Representativeness errors in comparisons between radar and gage measurements of rainfall. J. Hydrol., 134, 13-33.

Krajewski, W. F., and J. A. Smith, 2002: Radar hydrology: Rainfall estimation. Adv. Water Resour., 25, 1387-1394.

_ - G. J. Ciach, and E. Habib, 2003: An analysis of small-scale rainfall variability in different climatic regimes. Hydrol. Sci., 48, 151-162.

Le Bouar, E., J. Testud, and T. D. Keenan, 2001: Validation of the rain profiling algorithm "ZPHI" from the C-band polarimetric weather radar in Darwin. J. Atmos. Oceanic Technol., 18, 1819-1837.

Matrosov, S. Y., 2010: Evaluating polarimetric X-band radar rainfall estimators during HMT. J. Atmos. Oceanic Technol., 27, 122-134.

May, P. T., T. D. Keenan, D. S. Zrnić, L. D. Carey, and S. A. Rutledge, 1999: Polarimetric radar measurements of tropical rain at a 5-cm wavelength. J. Appl. Meteor., 38, 750-765.

Moore, R. J., D. A. Jones, D. R. Cox, and V. S. Isham, 2000: Design of the HYREX raingage network. Hydrol. Earth Syst. Sci., 4, 523-530.

Moreau, E., J. Testud, and E. Le Bouar, 2009: Rainfall spatial variability observed by X-band weather radar and its implication for the accuracy of rainfall estimates. Adv. Water Resour., 32, 1011-1019.

Nash, J. E., and J. V. Sutcliffe, 1970: River flow forecasting through conceptual models part I-A discussion of principles. J. Hydrol., 10, 282-290.

Rico-Ramirez, M. A., and I. D. Cluckie, 2008: Classification of ground clutter and anomalous propagation using dual-polarization weather radar. IEEE Trans. Geosci. Remote Sens., 46, 18921904

Ryzhkov, A., D. S. Zrnić, and R. Fulton, 2000: Areal rainfall estimates using differential phase. J. Appl. Meteor., 39, 263-268.

, S. E. Giangrande, and T. J. Schuur, 2005a: Rainfall estimation with a polarimetric prototype of WSR-88D. J. Appl. Meteor., 44, 502-515.

, T. J. Schuur, D. W. Burgess, P. L. Heinselman, S. E. Giangrande, and D. S. Zrnic, 2005b: The Joint Polarization Experiment: Polarimetric rainfall measurements and hydrometeor classification. Bull. Amer. Meteor. Soc., 86, 809-824. 
Sheppard, B. E., and P. I. Joe, 1994: Comparison of raindrop size distribution measurements by a Joss-Waldvogel disdrometer, a PMS 2DG spectrometer, and a POSS Doppler radar. J. Atmos. Oceanic Technol., 11, 874-887.

Silvestro, F., N. Rebora, and L. Ferraris, 2009: An algorithm for real-time rainfall rate estimation by using polarimetric radar: RIME. J. Hydrometeor., 10, 227-240.

Smith, J. A., M. Baeck, K. L. Meierdiercks, A. J. Miller, and W. F. Krajewski, 2007: Radar rainfall estimation for flash flood forecasting in small urban watersheds. Adv. Water Resour., 30, 2087-2097.

Sugier, J., and Tabary P., 2006: Evaluation of dual-polarisation technology at C-band for operational weather radar network. EUMETNET Opera 2 Rep., 44 pp. [Available online at http:// www.knmi.nl/opera/opera2/OPERA_2006_05_Evaluation_of_ dual_polarization_technology.pdf.]

Tan, J., J. W. F. Goddard, and M. Thurai, 1995: Applications of differential propagation phase in polarisation-diversity radars at S- and C-band. Proc. Int. Conf. on Antennas and Propagation, Eindhoven, Netherlands, IEE, 407.

Testud, J., E. Le Bouar, E. Obligis, and M. Ali-Mehenni, 2000: The rain profiling algorithm applied to polarimetric weather radar. J. Atmos. Oceanic Technol., 17, 332-356.

, S. Oury, R. A. Black, P. Amayenc, and X. Dou, 2001: The concept of "normalized" distribution to describe raindrop spectra: A tool for cloud physics and cloud remote sensing. J. Appl. Meteor., 40, 1118-1140.
Thompson, R., A. J. Illingworth, and M. Kitchen, 2008: Testing an algorithm for more accurate rainfall rates from an operational polarization radar. Proc. Fifth European Conf. on Radar in Meteorology and Hydrology, Helsinki, Finland, ERAD, 4 pp.

Thurai, M., and V. N. Bringi, 2005: Drop axis ratios from 2D video disdrometer. J. Atmos. Oceanic Technol., 22, 963-975.

— , G.-J. Huang, V. N. Bringi, W. L. Randeu, and M. Schönhuber, 2007: Drop shapes, model comparisons, and calculations of polarimetric radar parameters in rain. J. Atmos. Oceanic Technol., 24, 1019-1032.

Villarini, G., P. V. Mandapaka, W. F. Krajewski, and R. J. Moore, 2008: Rainfall and sampling uncertainties: A rain gauge perspective. J. Geophys. Res., 113, D11102, doi:10.1029/ 2007JD009214.

Vulpiani, G., P. Tabary, J. Parent du Chatelet, and F. S. Marzano, 2008: Comparison of advanced radar polarimetric techniques for operational attenuation correction at $\mathrm{C}$ band. J. Atmos. Oceanic Technol., 25, 1118-1135.

Williams, C. R., A. Kruger, K. S. Gage, A. Tokay, R. Cifelli, W. F. Krajewski, and C. Kummerow, 2000: Comparison of simultaneous rain drop size distributions estimated from two surface disdrometers and a UHF profiler. Geophys. Res. Lett., 27, 1763-1766.

Wood, S. J., D. A. Jones, and R. J. Moore, 2000: Accuracy of rainfall measurement for scales of hydrological interest. $H y$ drol. Earth Syst. Sci., 4, 531-543. 